\title{
Additive Manufacturing of Wind Turbine Molds
}

CRADA FINAL REPORT

NFE-16-06051

Approved for Public Release.

Distribution is Unlimited.
Brian Post (ORNL)

Bradley Richardson (ORNL)

Peter Lloyd (ORNL)

Lonnie Love (ORNL)

Stephen Nolet (TPI)

James Hannan (TPI)

June 2017 


\title{
DOCUMENT AVAILABILITY
}

Reports produced after January 1, 1996, are generally available free via US Department of Energy (DOE) SciTech Connect.

Website http://www.osti.gov/scitech/

Reports produced before January 1, 1996, may be purchased by members of the public from the following source:

\author{
National Technical Information Service \\ 5285 Port Royal Road \\ Springfield, VA 22161 \\ Telephone 703-605-6000 (1-800-553-6847) \\ TDD 703-487-4639 \\ Fax 703-605-6900 \\ E-mail info@ntis.gov \\ Website http://www.ntis.gov/help/ordermethods.aspx
}

Reports are available to DOE employees, DOE contractors, Energy Technology Data Exchange representatives, and International Nuclear Information System representatives from the following source:

Office of Scientific and Technical Information

PO Box 62

Oak Ridge, TN 37831

Telephone 865-576-8401

Fax 865-576-5728

E-mail reports@osti.gov

Website http://www.osti.gov/contact.html

This report was prepared as an account of work sponsored by an agency of the United States Government. Neither the United States Government nor any agency thereof, nor any of their employees, makes any warranty, express or implied, or assumes any legal liability or responsibility for the accuracy, completeness, or usefulness of any information, apparatus, product, or process disclosed, or represents that its use would not infringe privately owned rights. Reference herein to any specific commercial product, process, or service by trade name, trademark, manufacturer, or otherwise, does not necessarily constitute or imply its endorsement, recommendation, or favoring by the United States Government or any agency thereof. The views and opinions of authors expressed herein do not necessarily state or reflect those of the United States Government or any agency thereof. 
ORNL/TM-2017/290

CRADA/NFE-16-06051

\title{
Energy and Transportation Science Division Advanced Manufacturing Office
}

\section{Additive Manufacturing of Wind Turbine Molds}

\author{
Brian Post (ORNL) \\ Bradley Richardson (ORNL) \\ Peter Lloyd (ORNL) \\ Lonnie Love (ORNL) \\ Stephen Nolet (TPI Composites) \\ James Hannan (TPI Composites)
}

July 2017

\author{
Prepared by \\ OAK RIDGE NATIONAL LABORATORY \\ Oak Ridge, TN 37831-6283 \\ managed by \\ UT-BATTELLE, LLC \\ for the \\ US DEPARTMENT OF ENERGY \\ under contract DE-AC05-00OR22725
}




\section{CONTENTS}

CONTENTS

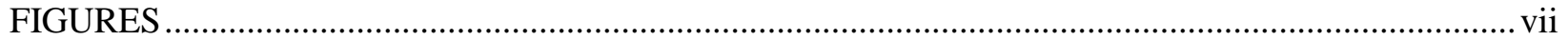

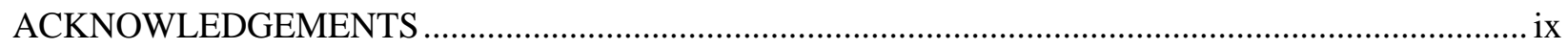

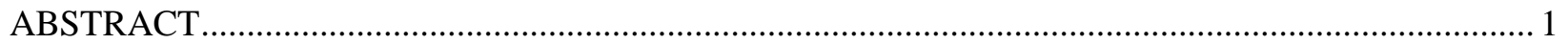

1. Additive Manufacturing of Wind Turbine Molds...................................................................... 3

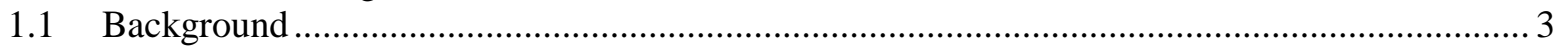

1.1.1 Conventional Wind Turbine Blade Manufacturing.............................................. 3

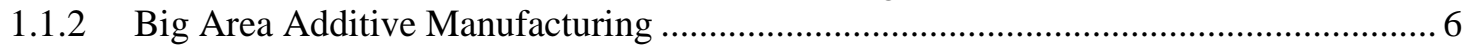

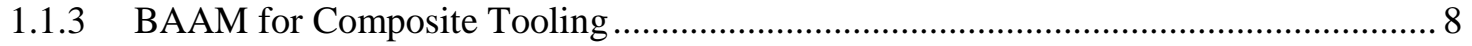

1.2 APPLICATIONS OF CURRENT ADDITIVE MANUFACTURING SYsTEMS IN

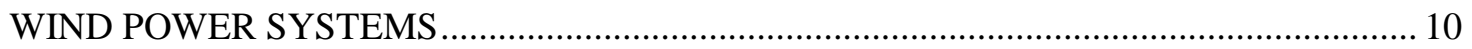

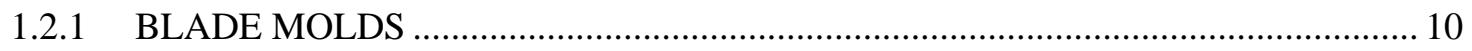

1.2.2 ORNL- TPI Scaled Wind Farm Technology (SWiFT) Facility Mold ........................ 11

1.2.3 Mold Requirements and Risk Reduction Exercise ................................................. 11

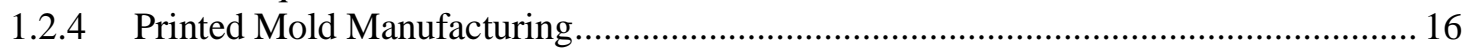

1.2.5 Economics of large scale AM blade mold production ............................................. 20

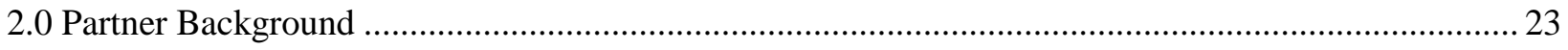

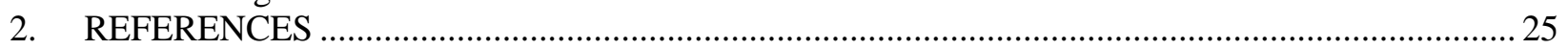




\section{FIGURES}

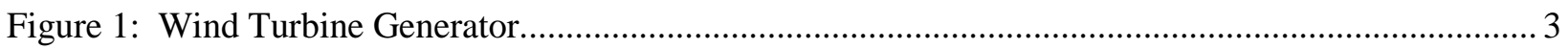

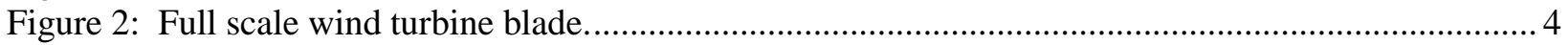

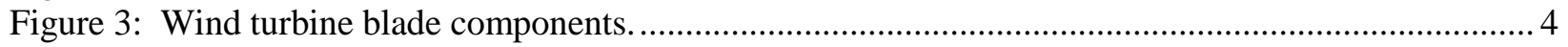

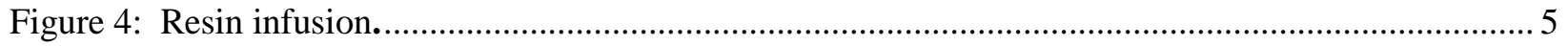

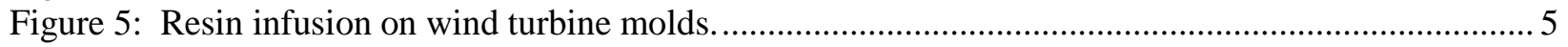

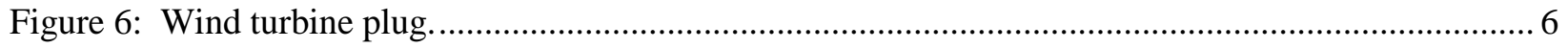

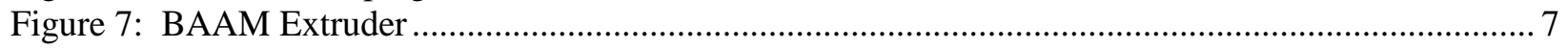

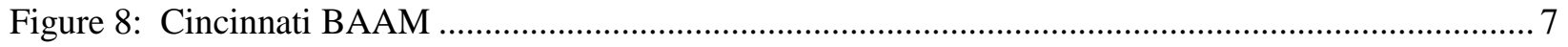

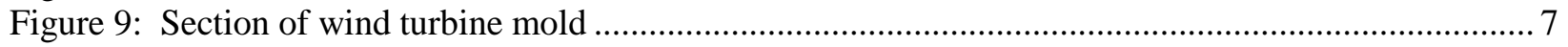

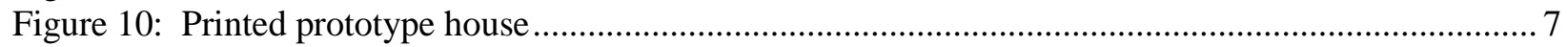

Figure 11: Energy intensity for manufacturing.

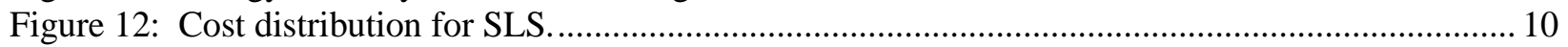

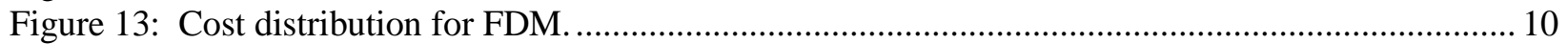

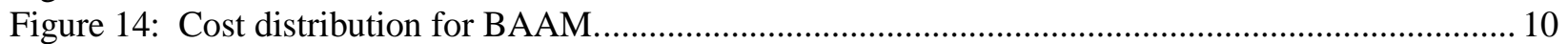

Figure 15: Additively manufactured blade mold and produced blade section...................................... 11

Figure 16: Integrated ORNL/TPI heater units in blade mold section. ............................................. 13

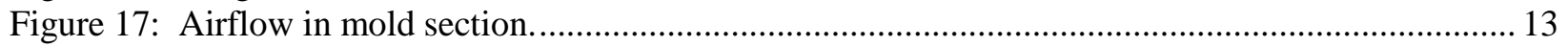

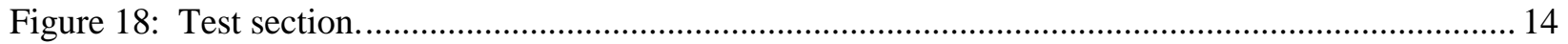

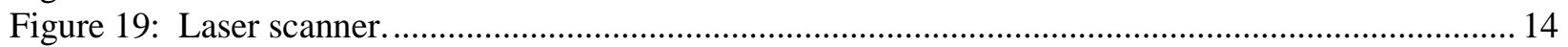

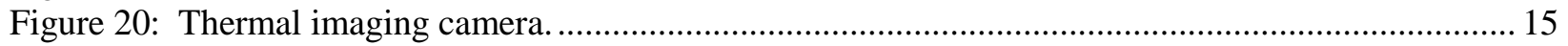

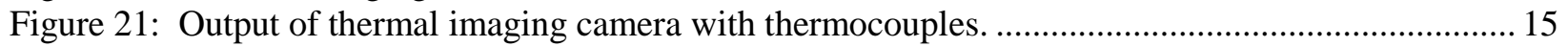

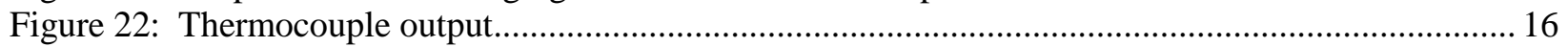

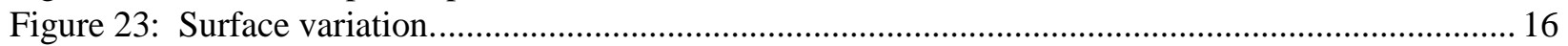

Figure 24: Printed low pressure side section 1 in the BAAM CI printer............................................ 17

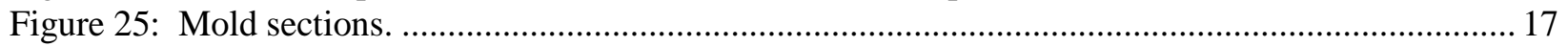

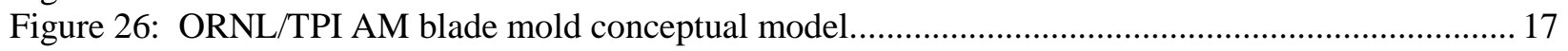

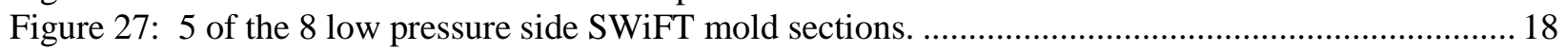

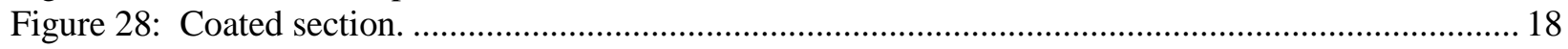

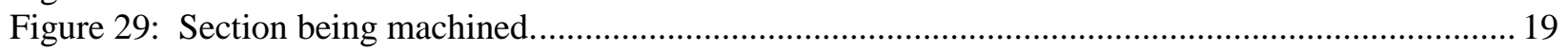

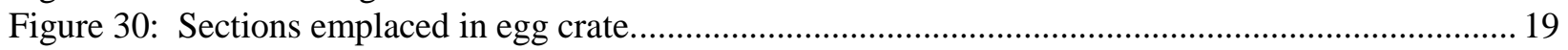

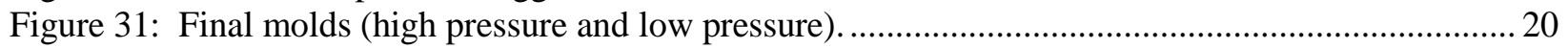

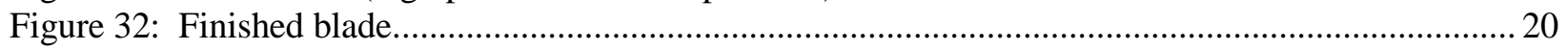

Figure 33: Costs for an AM 13m Blade Mold. ............................................................................... 21

Figure 34: Economic analysis of an AM printed 50m mold.......................................................... 22 


\section{ACKNOWLEDGEMENTS}

This CRADA NFE-16-6051 was conducted as a Technical Collaboration project within the Oak Ridge National Laboratory (ORNL) Manufacturing Demonstration Facility (MDF) sponsored by the US Department of Energy Advanced Manufacturing Office (CPS Agreement Number 24761). Opportunities for MDF technical collaborations are listed in the announcement "Manufacturing Demonstration Facility Technology Collaborations for US Manufacturers in Advanced Manufacturing and Materials Technologies" posted at http://web.ornl.gov/sci/manufacturing/docs/FBO-ORNL-MDF-2013-2.pdf. The goal of technical collaborations is to engage industry partners to participate in short-term, collaborative projects within the Manufacturing Demonstration Facility (MDF) to assess applicability and of new energy efficient manufacturing technologies. Research sponsored by the U.S. Department of Energy, Office of Energy Efficiency and Renewable Energy, Advanced Manufacturing Office, under contract DEAC05-00OR22725 with UT-Battelle, LLC.

The team would like to acknowledge DOE's Advanced Manufacturing Office and the Wind and Water Power Office. Both offices jointly sponsored and supported the program. The design of the blades was provided by Sandia National Laboratory with Wetzel providing structural analysis. TPI Composites provided extensive technical support for this project with engineering design of the molds, development of the concept of integrated ducting for heating, testing and evaluation of the fiberglass coating as well as completion of the mold manufacturing. 


\begin{abstract}
The objective of this project was to explore the utility of Big Area Additive Manufacturing (BAAM) for low cost manufacturing of wind turbine molds. Engineers at Oak Ridge National Laboratory (ORNL) and TPI Composites (TPI) collaborated to design and manufacture a printed mold that can be used for resin infusion of wind turbine components. Specific focus was on required material properties (operating temperatures and pressures, coefficient of thermal expansion (CTE), thermal conductivity), surface finish (accuracy and coatings) and system integration (integrated vacuum ports, and heating element). The project began with a simple proof of principle components, targeting surface coatings and material properties for printing a small section (approximately 4' x 4' x 2') of a mold. Next, the second phase scaled up and integrated with the objective of capturing all of the necessary components (integrated heating to accelerate cure time, and vacuum, sealing) for resin infusion on a mold of significant size ( $8^{\prime}$ x 20' x 6').
\end{abstract}




\section{ADDITIVE MANUFACTURING OF WIND TURBINE MOLDS}

This Oak Ridge National Laboratory Manufacturing Demonstration Facility (MDF) technical collaboration project (MDF-TC-2016-084) was begun on November 3, 2015 and was completed on May 31, 2017. The collaboration partner TPI Composites is a large business. This report includes both phase one and phase two of the project.

\subsection{BACKGROUND}

\subsubsection{Conventional Wind Turbine Blade Manufacturing}

A wind turbine generator has four main components (Figure 1). The first component is the wind turbine blades that transform wind currents to rotary motion on a shaft. The second component is the gear box and generator that transforms the rotary motion from the rotor and blades to electricity. The third component is the nacelle that is the housing for the generator, providing structure for coupling the generator to the final component, the tower.

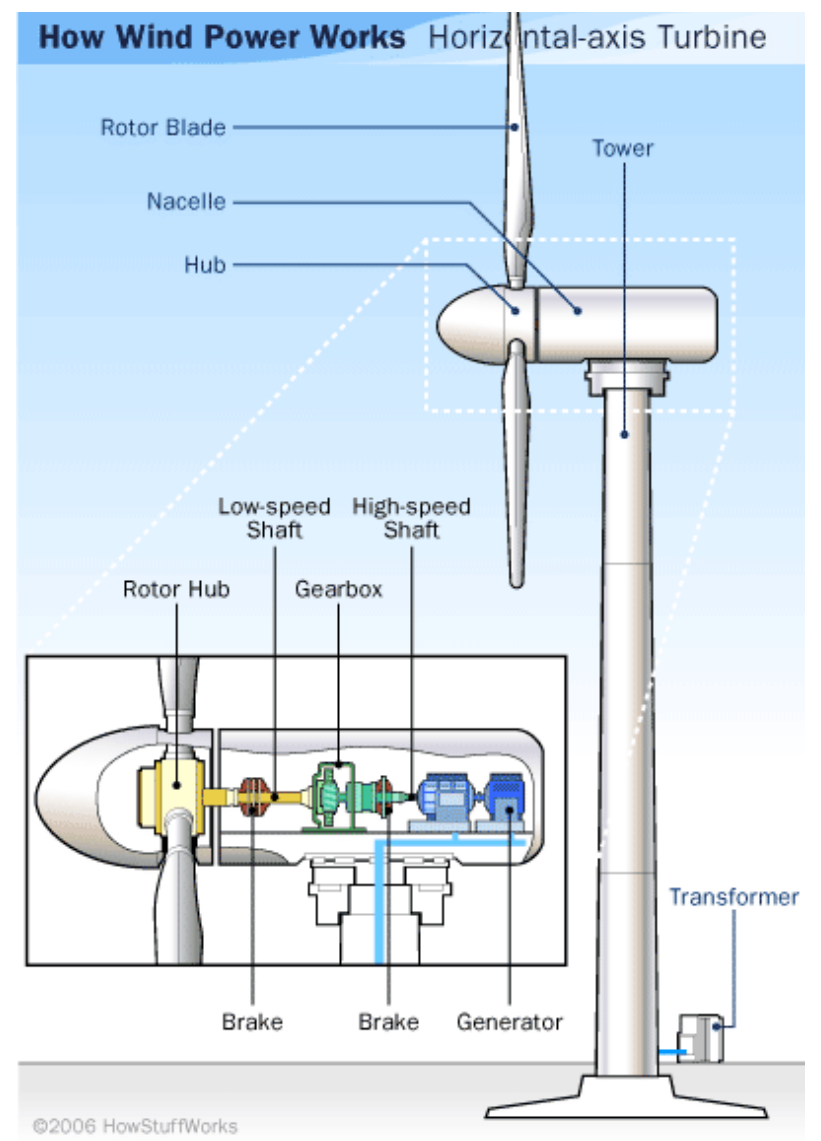

Figure 1: Wind Turbine Generator. ${ }^{1}$

\footnotetext{
${ }^{1}$ http://science.howstuffworks.com/environmental/green-science/wind-power2.htm
} 
One of the most critical components of the wind turbine generator is the wind turbine blade (Figure 2 and Figure 3). Each blade consists of a high pressure and low pressure side, typically manufactured out of fiberglass, that provides the pressure differential necessary to transform wind energy to lift on the blade. A spar runs the length of the blade to provide stiffness and load bearing capacity to transfer the wind loads to the rotor coupled to the generator. The primary focus of this project was the manufacture of the wind turbine blades.

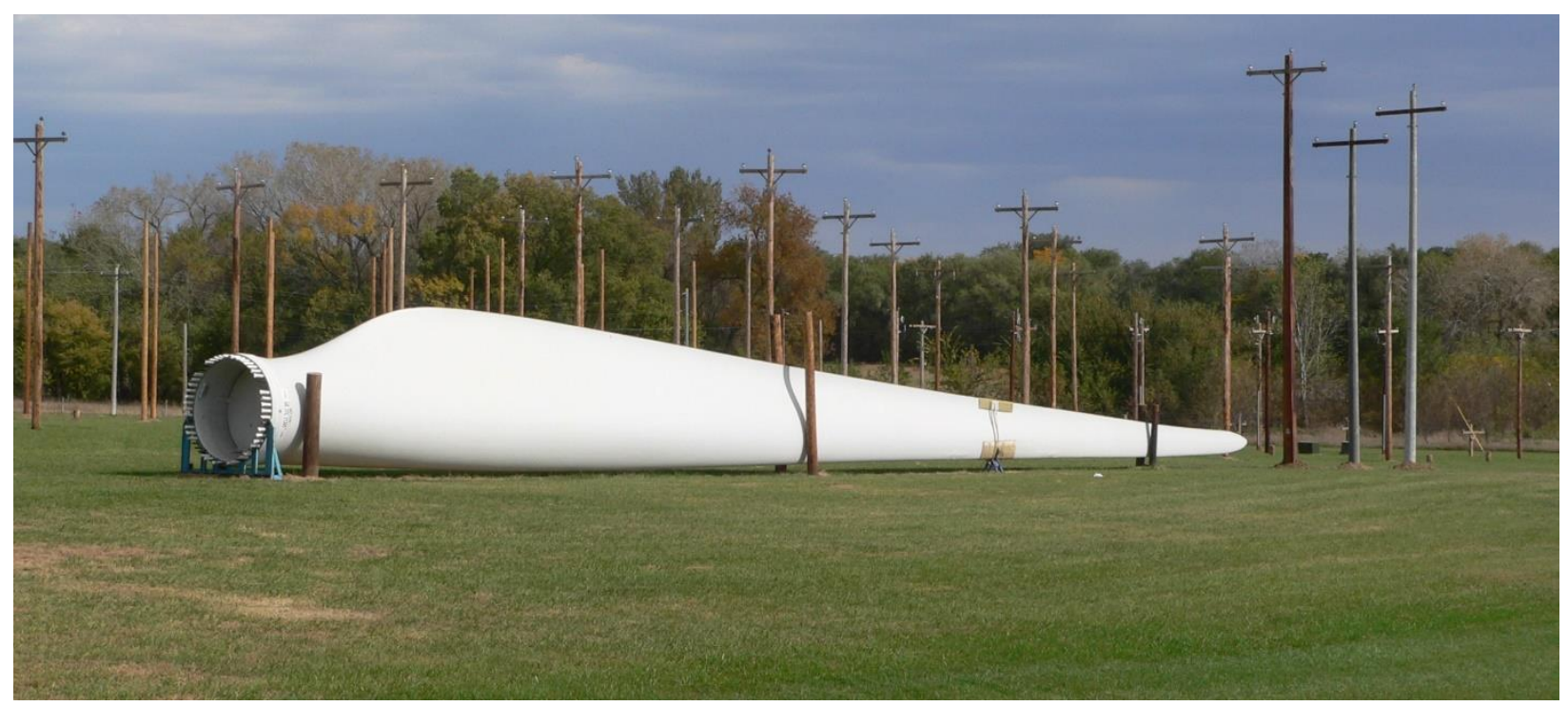

Figure 2: Full scale wind turbine blade. ${ }^{2}$

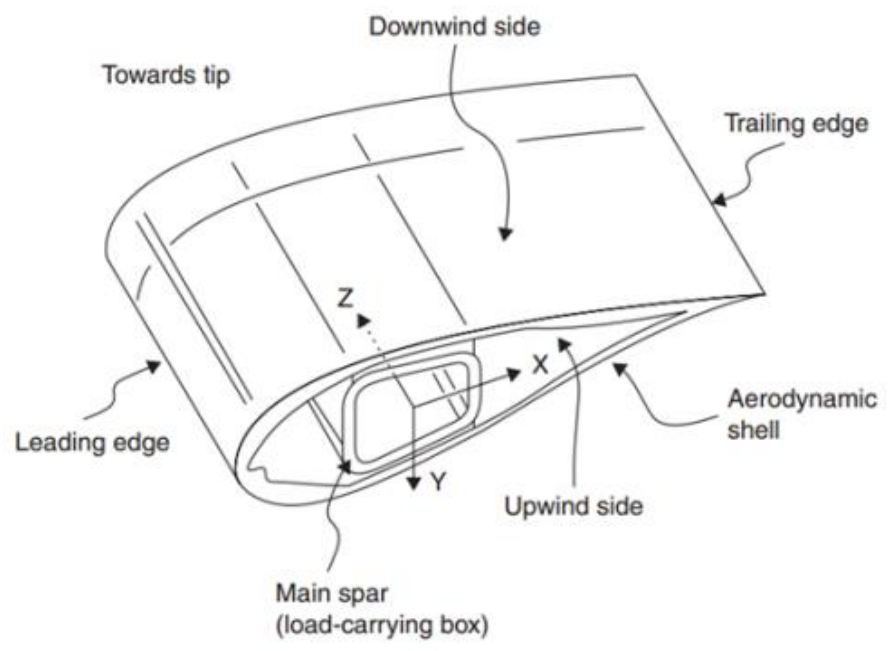

Figure 3: Wind turbine blade components. ${ }^{3}$

There are two main methods for manufacturing wind turbine blades: prepreg and resin infusion. The infusion process is commonly perceived as the most cost effective process due to the lower cost of the bill

\footnotetext{
${ }^{2}$ http://www.powerblanket.com/curing-epoxy-resin-on-wind-turbine-blades

${ }^{3}$ http://www.renewableenergyfocus.com/view/42937/materials-innovations-for-more-efficient-wind-turbines/
} 
of materials (BOM). The general principle behind resin infusion is to use vacuum to pull a resin into the reinforcing fibers as illustrated in Figure 4. Clearly a key feature of resin infusion is the mold tool that provides the shape of the blade for the infusion process. These molds are typically extremely large and complex with integrated heating elements and integrated vacuum ports (Figure 4 and Figure 5).

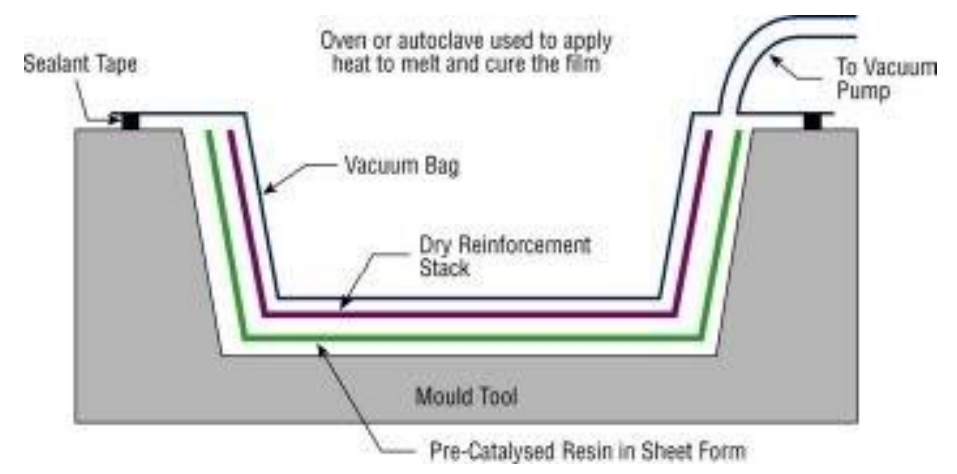

Figure 4: Resin infusion.

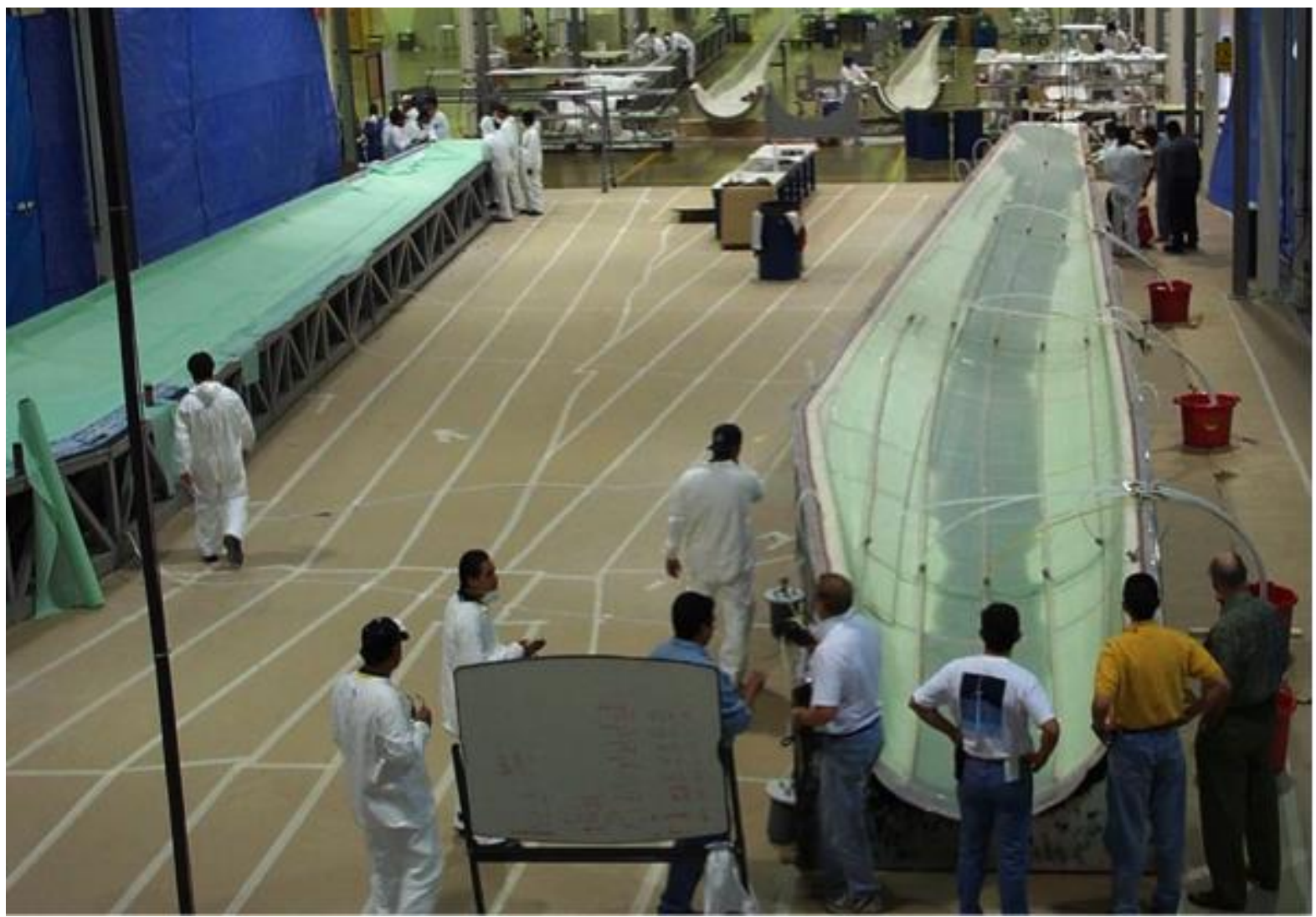

Figure 5: Resin infusion on wind turbine molds.

The process for manufacturing wind turbine molds is relatively complex. The first step is to manufacture a plug. The plug is a master design of the blade (Figure 6). To manufacture a mold, a fiberglass shell is built on top of the plug and attached to a rigid truss structure (also known as an egg crate). Conductive wires are installed on the back side of the mold to provide heat to accelerate the curing cycle. 


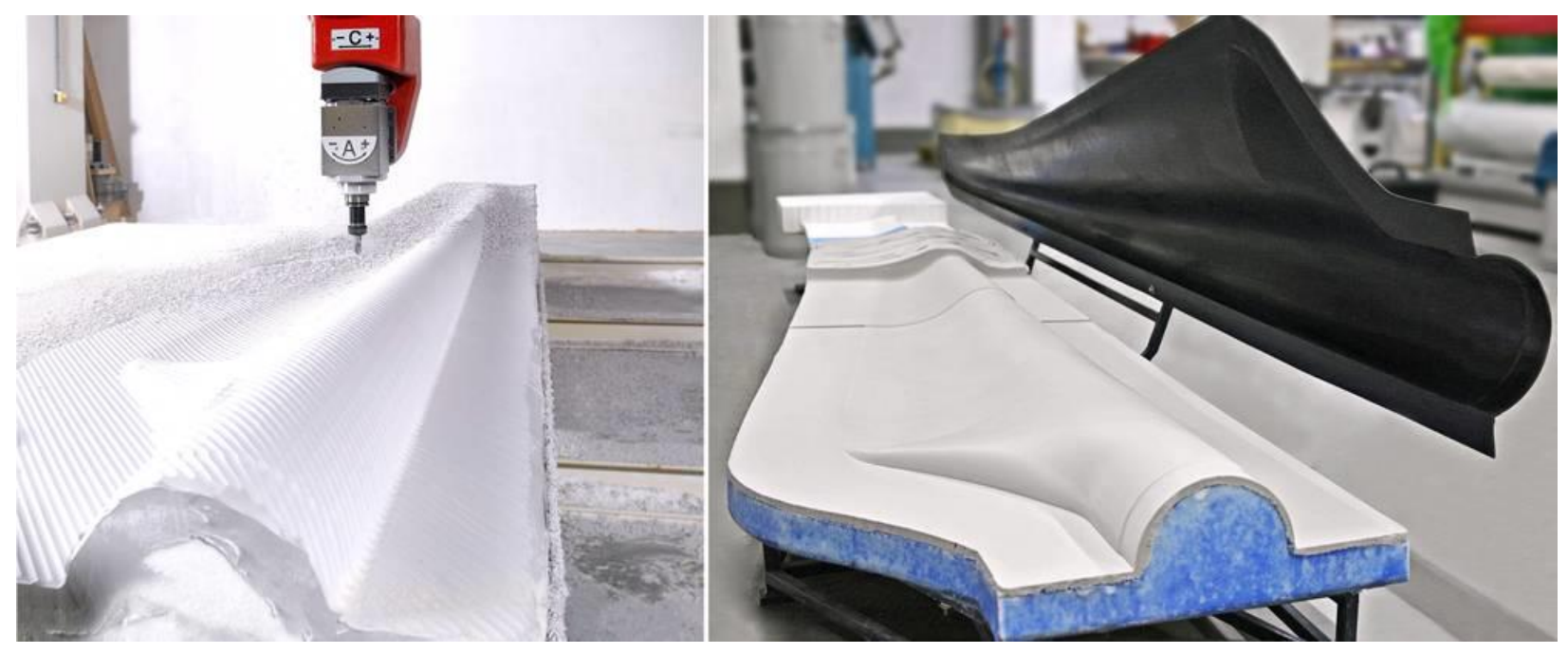

Figure 6: Wind turbine plug.

\subsubsection{Big Area Additive Manufacturing}

Conventional fused deposition modeling is based on melting and extruding a filament of thermoplastic feedstock. Prior work shows that the peak flow rate is limited by the rate at which the filament can be melted (Monzon 2013). For larger print volumes (at least 15 times the build volume of desktop-size consumer-level AM systems), technologies are developing. For example, Cincinnati Incorporated partnered with Oak Ridge National Laboratory to develop the Big Area Additive Manufacturing (BAAM) process in 2014 that scales the extrusion process from desktop-sized AM systems of 1-5 cubic inches per hour to over 1000 cubic inches per hour. To achieve high print rates, material pellets are used, which also significantly lowers the material cost (from $\$ 110-\$ 220 / \mathrm{lb}$ to $\$ 3-\$ 5 / \mathrm{lb}$ ), in combination with an optimized feed screw that reduces throttling of the pellet flow into the material. BAAM is an extrusion process that uses injection molding material for the feedstock and a single screw extruder for melting and metering the flow rate (see Figure 7). (Holshouser, Newell et al. 2013) A gantry system, commercialized by Cincinnati Incorporated (see Figure 8), moves the extruder in $\mathrm{x}, \mathrm{y}$ and $\mathrm{z}$ directions to build the part. The extruder is capable of delivering $100 \mathrm{lbs} /$ hour of thermoplastic materials from pellet feedstock. The gantry system is capable of achieving $200 \mathrm{inch} / \mathrm{sec}$ peak velocities with $64.4 \mathrm{in} / \mathrm{s}^{2}$ accelerations and position accuracy in the 0.002 ". As previously reported, the use of carbon fiber reinforcement in the thermoplastic resins increases the part strength and stiffness.(Tekinalp, Kunc et al. 2014) But, just as important, it increases thermal conductivity and reduces the coefficient of thermal expansion relaxing the need for a heated chamber to produce large parts (Figure 9 and Figure 10). (Love, Kunc et al. 2014) The elimination of the oven significantly decreases the energy intensity (manufacturing energy required per $\mathrm{kg}$ of product). As shown in Figure 11, conventional FDM systems with heated chambers have a $100 \mathrm{~kW}-\mathrm{hr} / \mathrm{kg}$ energy intensity. Desktop systems that have similar production rates have a $5.5 \mathrm{~kW}-\mathrm{hr} / \mathrm{kg}$ energy intensity suggesting that the oven accounts for $95 \%$ of the energy utilization in FDM production. BAAM further reduces the energy intensity to 1.1 $\mathrm{kW}-\mathrm{hr} / \mathrm{kg}$ by significantly increasing productivity from $1 \mathrm{ci} / \mathrm{hr}$ to $2500 \mathrm{ci} / \mathrm{hr}$ and manufactured at room temperature. Due to its higher build rates and build sizes, BAAM's initial targeted applications is in the tooling industry, specifically where large, complex injection molds are needed to produce CM polymeric and metal parts at low cost. 


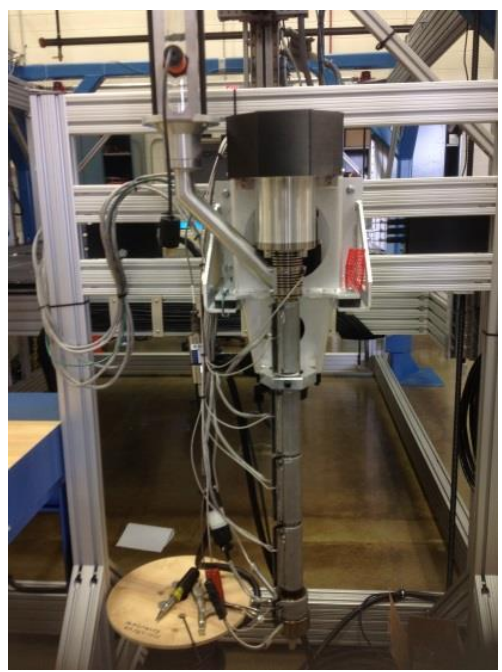

Figure 7: BAAM Extruder.

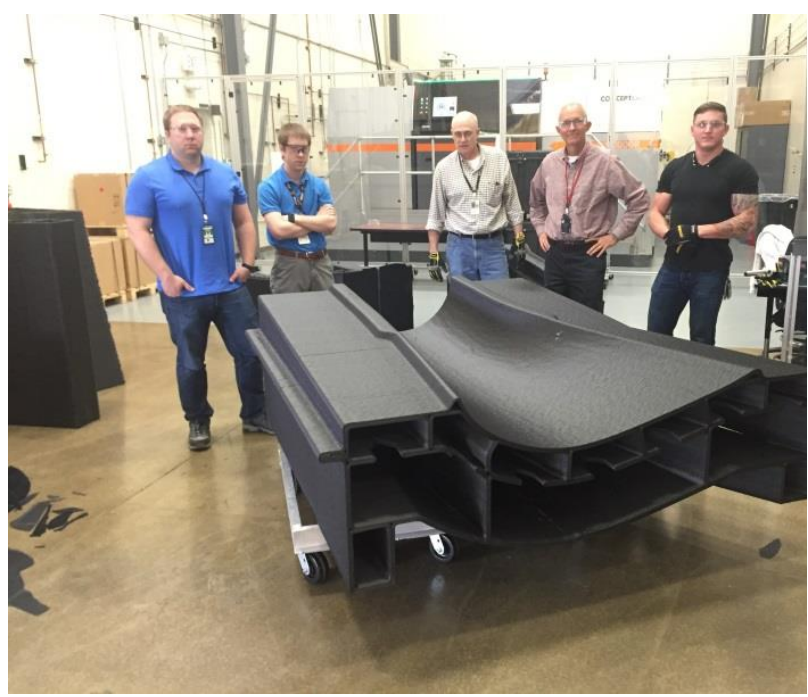

Figure 9: Section of wind turbine mold.

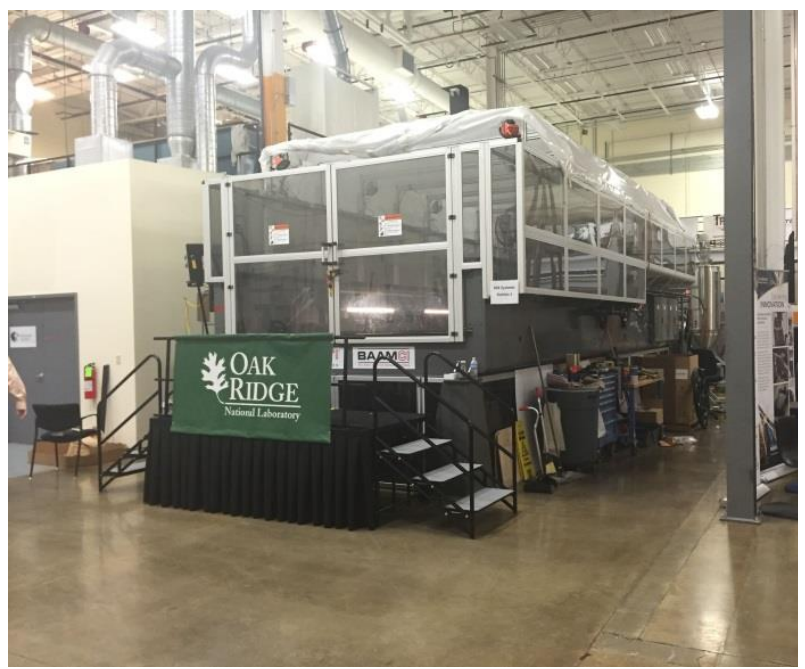

Figure 8: Cincinnati BAAM.

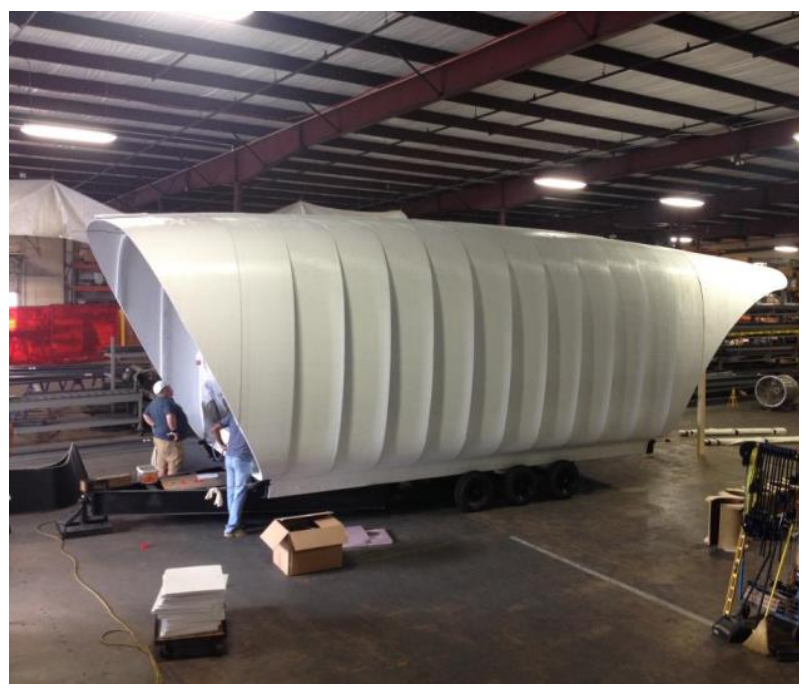

Figure 10: Printed prototype house. 


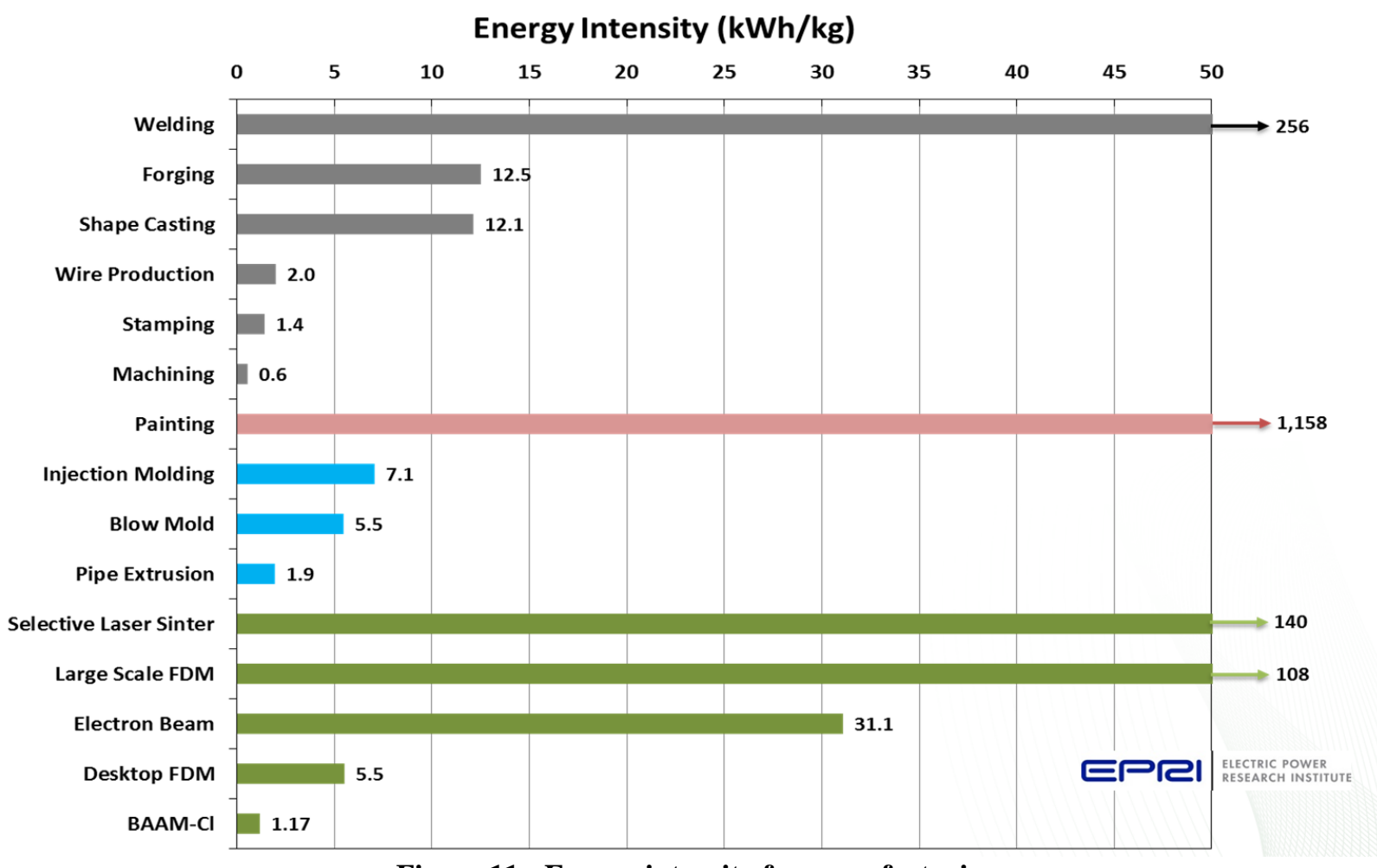

Figure 11: Energy intensity for manufacturing.

Therefore, the combination of lower energy intensity, higher productivity and lower material cost suggests that there will be a significant production cost reduction with BAAM when compared to conventional AM systems.

\subsubsection{BAAM for Composite Tooling}

Tooling is the foundation of many manufacturing industries. Molds are used in the aerospace, automotive and appliance industries to shape metal, plastic and composite parts. As an example, the automotive industry generally spends $\$ 200 \mathrm{M}$ on tooling for each car model. By 2018, tooling for the automotive industry is expected to exceed $\$ 15.2 \mathrm{~B}$ per year. Tooling is generally very expensive ( $\$ 10 \mathrm{~K}$ 's to $\$ 100 \mathrm{~K}$ 's per mold) and has long lead (months to years) items. There is great potential for revolutionizing the tool and die industry through the use of additive manufacturing.

The aerospace industry, due to weight concerns, has begun to migrate from aluminum to carbon fiber composites. The conventional approach for manufacturing composite structures is to lay up the carbon fiber, core structure and resin on a mold. The molds and composite materials are processed inside an autoclave to rapidly cure the resins and remove any air. The requirements for the molds are elevated operating temperatures (from $200 \mathrm{C}$ to $375 \mathrm{C}$ ), vacuum integrity ( 15 mbar over 60 minutes) and moderate pressures (100 psi) with tight dimensional tolerances (under 0.005 " distortion). A conventional composite tool will cost in excess of $\$ 100 \mathrm{~K}$ (US) and take several months to manufacture. ORNL recently partnered with Boeing, Ford, Techmer and BASF to evaluate the feasibility and economics of using BAAM to produce composite tools. A variety of materials were evaluated including PEEK, PEEK, Ultem, Apollo, PPS, PPSF and PPSU. The final material of choice, based on performance and cost, was PPS loaded with $50 \%$ carbon fiber. The material cost was approximately $\$ 8 / \mathrm{lb}$. The sample tool weighed approximately 65 lbs and took 2 hours to print. Preprocessing time (setting up the machine and slicing the model) was 
approximately 2 hours. The mold was grown approximately 0.100 " oversized and machined using a Thermwood router to the final size. It took approximately 2 hour to transfer the mold to the router and another 5 hours to machine. Assuming labor rates of $\$ 50 / \mathrm{hr}$ and machining rates of $\$ 150 / \mathrm{hr}$, the total tool cost was approximately $\$ 1870$ (Table 1). In terms of manufacturing time, from beginning to end, it took approximately two days to fully manufacture the mold. In comparison to SLS in the BAAM provides a more balanced distribution of costs. AM machine time is equivalent to material cost and the cost of printing is close to the cost of finishing.

Table 1: BAAM tool cost breakdown

\begin{tabular}{|l|l|l|l|}
\hline & Time/material & Cost & Percentage \\
\hline Preprocessing & 2 hours & $\$ 100$ & 5.3 \\
\hline Material & $65 \mathrm{lbs}$ & $\$ 520$ & 27.8 \\
\hline Processing & 2 hours & $\$ 400$ & 21.4 \\
\hline Post processing (labor) & & & 45.5 \\
\hline$-\quad$ Labor & 2 hours & $\$ 100$ & \\
\hline$-\quad$ Machine & 5 hours & $\$ 750$ & \\
\hline Total & 9 hours & $\$ 1870$ & \\
\hline
\end{tabular}

A similar analysis can be conducted for the same tool to be manufactured out of PPS on a Fortus $900 \mathrm{mc}$. First, material cost is approximately $\$ 650$ for 93 cubic inches of material. The tool has 1725 cubic inches of material bringing the material cost up to $\$ 12,018$. Production time with 0.020 " nozzle will be 460 hours. An industrial FDM system capable of manufacturing this mold will cost approximately $\$ 350 \mathrm{~K}$ with $\$ 35 \mathrm{~K} /$ year service contracts. Assume that the system will be in service for 5 years with a $\$ 100 \mathrm{~K}$ trade in value and a $4 \%$ interest rate, the machine will have a monthly cost of $\$ 7800$. With a machine utilization of $50 \%$, the hourly cost of running the machine, excluding overhead associated with utilities and space charges is $\$ 23 / \mathrm{hr}$. Therefore, conservatively assume the total hourly charge rate for an industrial FDM system is $\$ 40 / \mathrm{hr}$. This would bring the operating cost of the machine to $\$ 18,400$ and a total part production cost to $\$ 31,368$. This is still a very attractive cost for composite tooling but highlights how manufacturing time (460 hours for FDM vs 9 hours for BAAM) and low feedstock cost ( $\$ 8 / \mathrm{lb}$ versus $\$ 180 / \mathrm{lb}$ ) can result in a $17 \mathrm{X}$ reduction of $\mathrm{AM}$ costs $(\$ 31,368$ for FDM vs. $\$ 1870$ for BAAM) and 50X increase in production rate. Figure 12 through Figure 14 show the cost distribution between SLS, FDM and BAAM.

Table 2: FDM tool cost breakdown

\begin{tabular}{|l|l|l|l|}
\hline & Time/material & Cost & Percentage \\
\hline Preprocessing & 2 hours & $\$ 100$ & 3.2 \\
\hline Material & $65 \mathrm{lbs}$ & $\$ 12,018$ & 38.3 \\
\hline Processing & 460 hours & $\$ 18,400$ & 58.7 \\
\hline Post processing (labor) & & & 2.7 \\
\hline$-\quad$ Labor & 2 hours & $\$ 100$ & \\
\hline$-\quad$ Machine & 5 hours & $\$ 750$ & \\
\hline Total & 9 hours & $\$ 31,368$ & \\
\hline
\end{tabular}




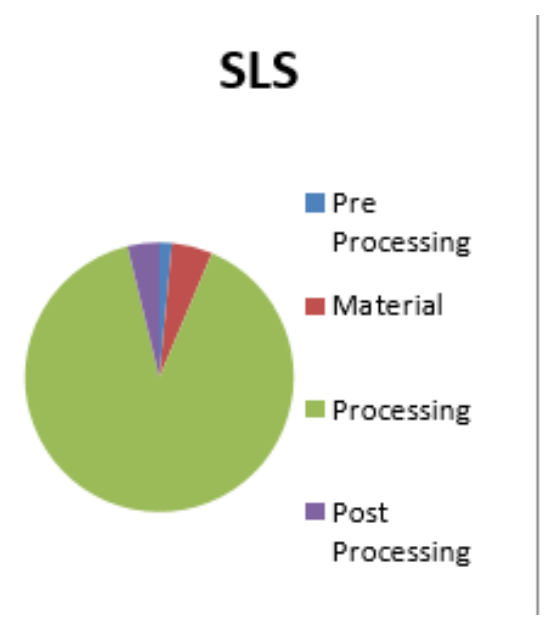

Figure 12: Cost distribution for

SLS.

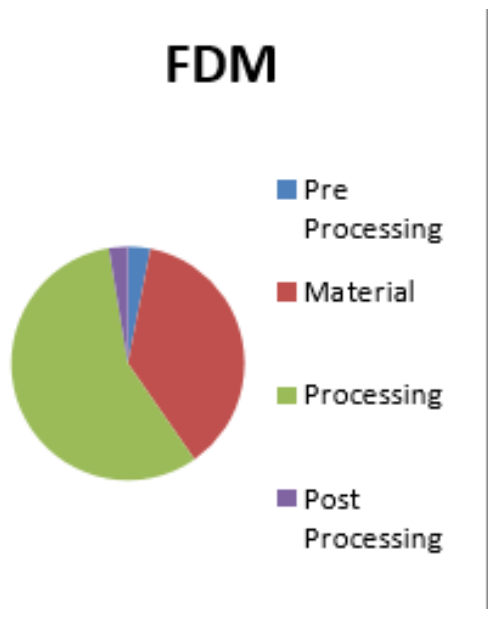

Figure 13: Cost distribution for FDM.

\section{BAAM}

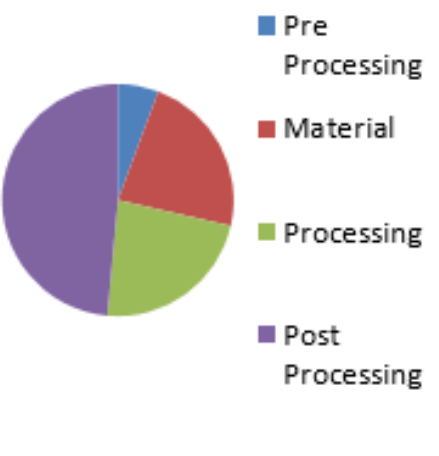

Figure 14: Cost distribution for BAAM.

\subsection{APPLICATIONS OF CURRENT ADDITIVE MANUFACTURING SYSTEMS IN WIND POWER SYSTEMS}

To date AM, is hindered by limited production rates, expensive materials and processing costs, and small build volumes. These conditions serve to significantly limit the applicability of AM to wind energy system production. Commercial turbines are large systems where individual components often exceed 50 meters in length. The sheer size and mass of these components combined with throughput requirements largely preclude the application of current AM technology in wind power manufacturing. However, several application areas have been identified where economic and technological incentives make AM processes viable for current production

\subsubsection{BLADE MOLDS}

The first identified wind application for AM is in the manufacture of molds for wind turbine blades. As described previously, tooling is a primary target for the current state of AM technology given the less stringent requirements for material performance molds of various sizes and shapes have been produced for a variety of industries. Large tooling however, remained out of reach until the development of large scale composite AM manufacturing processes like the BAAM-CI. Figure 15 shows the ORNL/TPI AM blade mold demonstrator produced as a collaboration between ORNL and TPI and funded by DOE's Advanced Manufacturing, Wind Energy, and Water Power offices. 


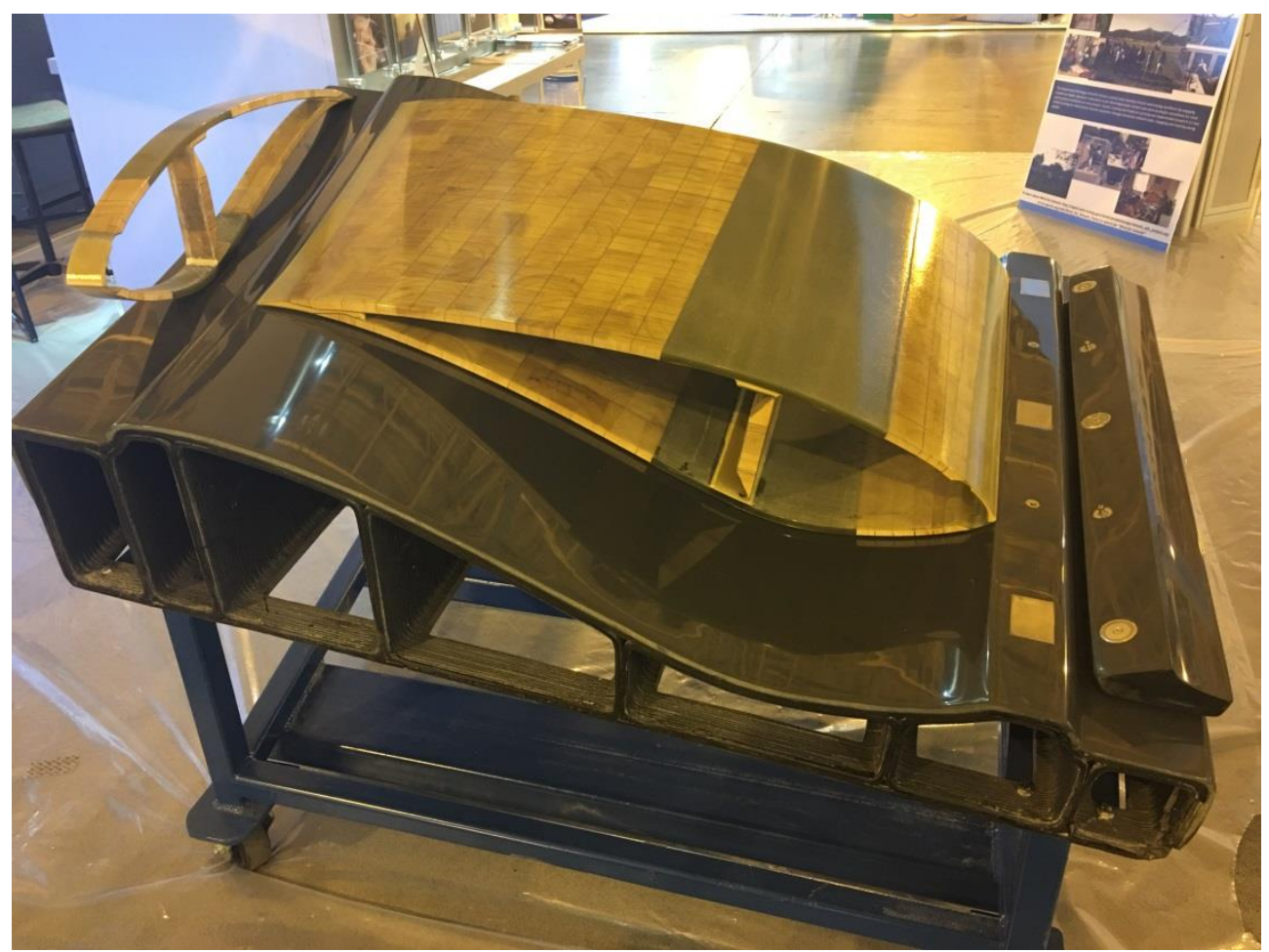

Figure 15: Additively manufactured blade mold and produced blade section.

The traditional blade mold manufacturing process, described previously, is a multi-step expensive operation. First, a plug is manufactured by subtractive machining of foam and tooling resin. This multipiece assembly is takes several weeks to months to produce from Computer Aided Design (CAD) drawings used to generate Computer Numerical Control (CNC) toolpaths. From there, the plug is shipped to the mold manufacturer where it is qualified and aligned. The mold manufacturer then applies a release agent and lays up fiberglass of sufficient thickness to support the molding operations. Miles of heating wire is manually embedded in the underside of the mold and arranged in zones of similar area. Then a steel frame is manually erected and attached to the mold, prior to removal from the plug. From one plug set, up to eight molds can be produced amortizing the cost. For the production of one prototype mold, or a small set of molds this cost can be prohibitively expensive (often millions of dollars).

\subsubsection{ORNL- TPI Scaled Wind Farm Technology (SWiFT) Facility Mold}

In order to study the effect of wakes in large wind farms the Sandia National Laboratory SWiFT facility uses a scaled wind farm. These turbines require custom blades to simulate the dynamics of their larger counterparts. The blades were scheduled to be produced using additively manufactured molds produced in partnership between ORNL and TPI and funded by the Department of Energy's (DOE) Advanced Manufacturing (AMO) and Wind and Water Power Office (WWPO). This research effort serves as a case study to examine not only the technological impacts of AM on wind blade production, but also the economics of AM at the large scale using the BAAM technology.

\subsubsection{Mold Requirements and Risk Reduction Exercise}

The first step to the project was to define the mold requirements. For the resin infusion, there were a number of critical performance targets for the mold necessary to successfully manufacture blades. These targets included operating temperature, temperature gradients across the surface of the molds during service, mold distortion, vacuum and life. The team identified three goals for each metric. The first was 
the target necessary for the success of the project. The second was a stretch goal that, if passed, would qualify the process for low volume production. Finally, the ultimate goal for the technology was the targets necessary for full scale production. The metrics and goals for the project are outlined in Table 3.

The first phase of the project focused on risk reductions steps. The team designed a series of experiments to ensure that the BAAM manufactured molds to achieve the targets. High risk items included the heating (achieving the target temperatures and temperature gradients), distortion and vacuum integrity. In terms of vacuum integrity, the team elected to coat the printed mold with fiberglass. The mold was designed 4 $\mathrm{mm}$ under the target mold lines. TPI coated the molds with $8 \mathrm{~mm}$ of fiberglass that would then be machined to the final surface geometry and finish. The second item was the heating of the mold. It was determined that the additive manufacturing could enable a very novel approach to heating. Rather than manually inserting miles of conductive wires, the molds could be designed with ducting built directly onto the structure. Small heating elements and blowers could be easily and rapidly installed in the molds, taking the time for installation of heaters from weeks and months to a single day.

Table 3: Performance Metrics and Goals ${ }^{4}$

\begin{tabular}{|l|l|l|l|}
\hline Parameter & $\begin{array}{l}\text { Target (this } \\
\text { project) }\end{array}$ & Stretch (low volume) & Production \\
\hline $\begin{array}{l}\text { Substrate bond } \\
\text { interface and } \\
\text { coatings }\end{array}$ & $\begin{array}{l}\text { Short beam shear } \\
\text { test with no failure } \\
\text { of interface at } \\
\text { ambient }\end{array}$ & $\begin{array}{l}\text { Short beam shear test } \\
\text { with no failure of } \\
\text { interface at 40 C }\end{array}$ & $\begin{array}{l}\text { Short beam shear test } \\
\text { with no failure of } \\
\text { interface at 70 C }\end{array}$ \\
\hline $\begin{array}{l}\text { Mold temp (+/-5 } \\
\text { C) }\end{array}$ & $\begin{array}{l}\text { Ambient (need } \\
\text { oven) }\end{array}$ & 40 C (resin flows) & $\begin{array}{l}70 \mathrm{C} \text { (fast cure) with } \\
100 \mathrm{C} \text { peak }\end{array}$ \\
\hline Mold distortion & $\begin{array}{l}\text { Match HP to LP at } \\
\text { ambient less than } \\
1 \% \text { of chord }\end{array}$ & $\begin{array}{l}\text { Match HP to LP at } 40 \\
\text { C less than 1\% of } \\
\text { chord }\end{array}$ & $\begin{array}{l}\text { Match HP to LP at } 70 \\
\text { C less than 1\% of } \\
\text { chord }\end{array}$ \\
\hline Vacuum drop & $\begin{array}{l}30 \text { mbar over } 30 \\
\text { minutes }\end{array}$ & $\begin{array}{l}15 \text { mbar over } 60 \\
\text { minutes }\end{array}$ & $\begin{array}{l}15 \text { mbar over } 60 \\
\text { minutes }\end{array}$ \\
\hline $\begin{array}{l}\text { Assembly of mold } \\
\text { pieces }\end{array}$ & $\begin{array}{l}\text { Meet gap } \\
\text { tolerance (defined } \\
\text { next page) at } \\
\text { Room temp }\end{array}$ & $\begin{array}{l}\text { Meet gap tolerance at } \\
40 \text { C }\end{array}$ & $\begin{array}{l}\text { Meet gap tolerance at } \\
70 \mathrm{C}\end{array}$ \\
\hline Life & $\begin{array}{l}\text { blades } \\
12 \text { blades }\end{array}$ & 1000 (production) \\
\hline
\end{tabular}

\footnotetext{
${ }^{4} \mathrm{HP}$ - high pressure side, LP - low pressure side
} 


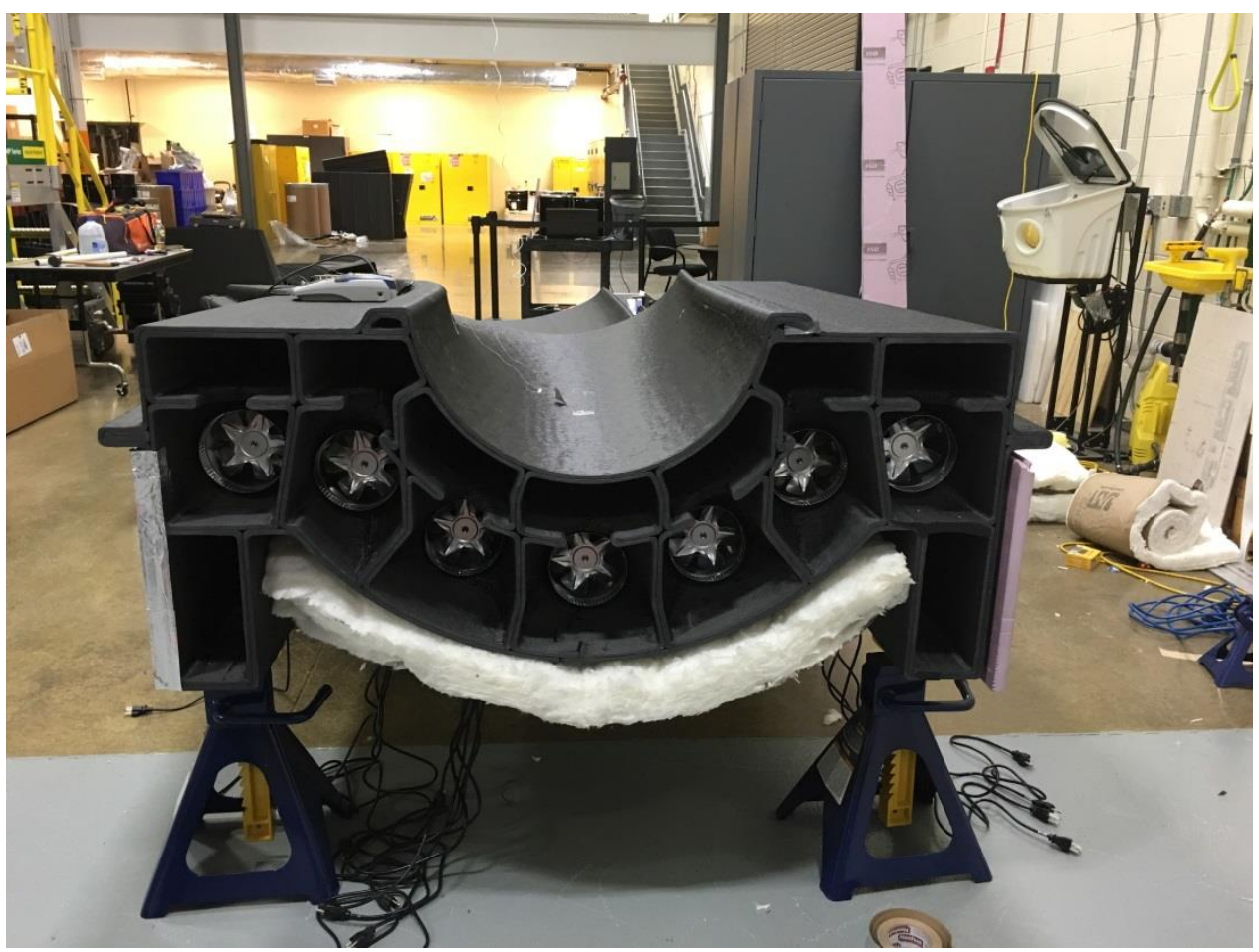

Figure 16: Integrated ORNL/TPI heater units in blade mold section.

Figure 16 demonstrates the arrangement of heater units in the SWiFT mold set for the uniform heating of the mold surface. Each channel has been designed to be of equal surface area to reduce nonuniformity of the temperature profile over the surface of the mold. Hot air is circulated through the mold until the surface temperature reaches the desired set point, at which point the set point is lowered to a maintenance level.

Figure 17: Airflow in mold section.

A cross sectional view of the second mold section is shown in Figure 17. Arrows describe the heat flow, in that hot air exits the heater unit and flows along the surface of the mold where it loses energy and recirculates forming a closed loop. In doing so the functional structure of the AM component is utilized not only to achieve the desired surface geometry, but also to provide a housing for the heating unit and to distribute the heat uniformly throughout the structure. AM in this example enables functional structure and eliminates the manual labor associated with the emplacement of the heating system. Furthermore, a failed heating unit is easily replaceable via a pocket on the underside of the return channel. 
A single section was manufactured and evaluated for performance (Figure 18). A series of experiments were conducted to evaluate the performance (distortion, temperature gradient, vacuum integrity) of the mold. A laser scanner (Figure 19) profiled the accuracy of the mold at room temperature. The heaters were turned on and the system was then brought up to the target temperature. At temperature, the laser scanner measured the hot surface profile and thermal imaging cameras measured the temperature gradients across the surface (Figure 20, Figure 21 and Figure 22). The temperature gradient was measured at $+/-3 \mathrm{C}$ at $40 \mathrm{C}$ exceeding the requirements for the stretch goal. As shown in Figure 23, surface variations are under $+/-0.025$ ", approximately $0.1 \%$ of the chord. In terms of vacuum, the system exceeds the target of 15 mbar over 60 minutes. Therefore, the risk reduction exercise demonstrated that the AM mold sections exceeded the stretch goal requirements.

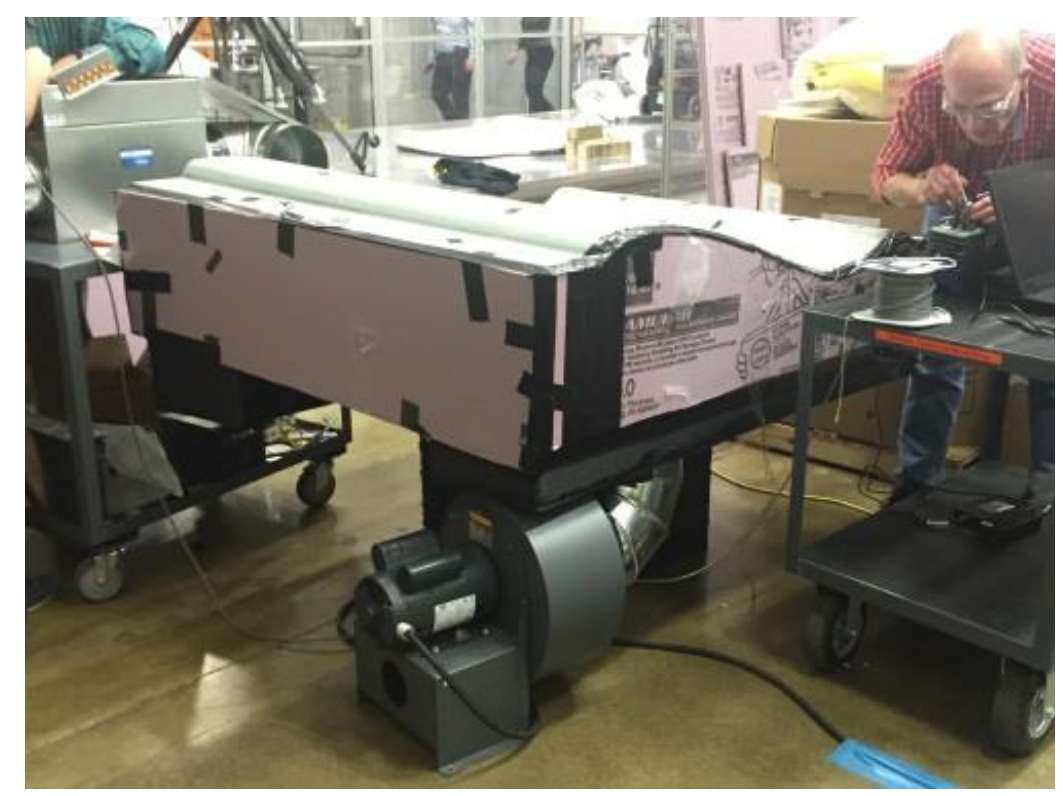

Figure 18: Test section.

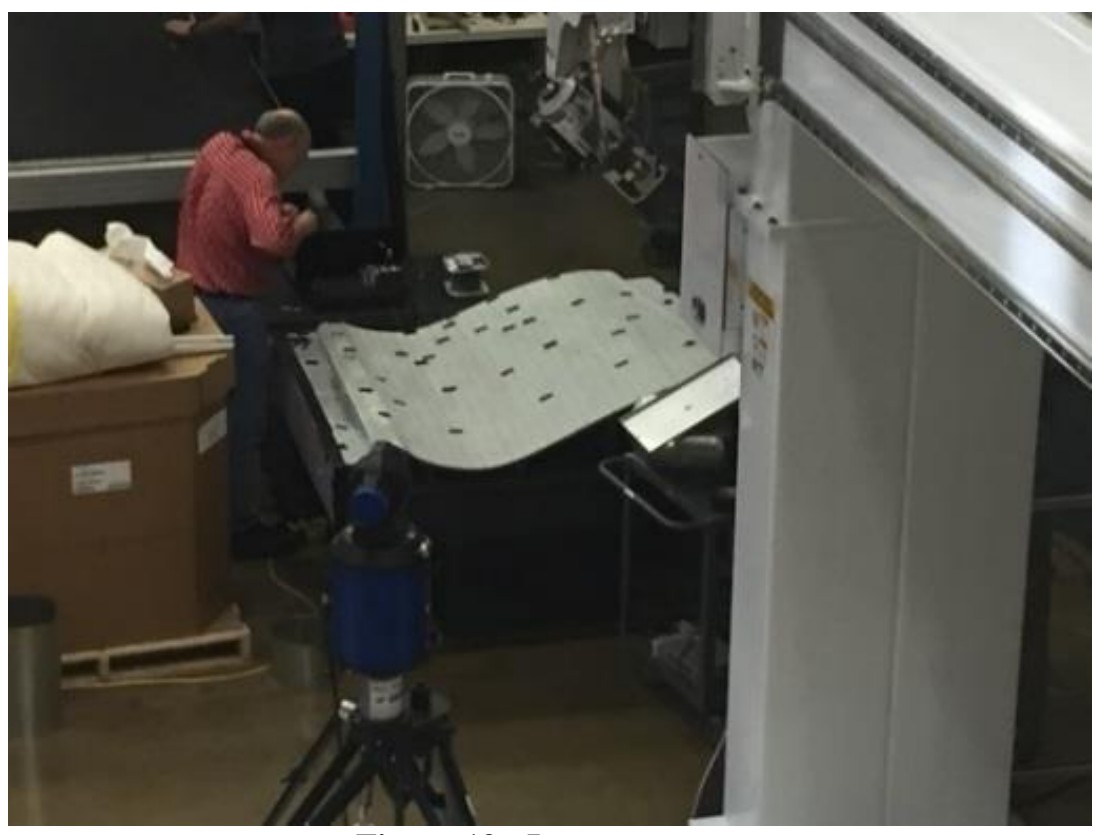

Figure 19: Laser scanner. 


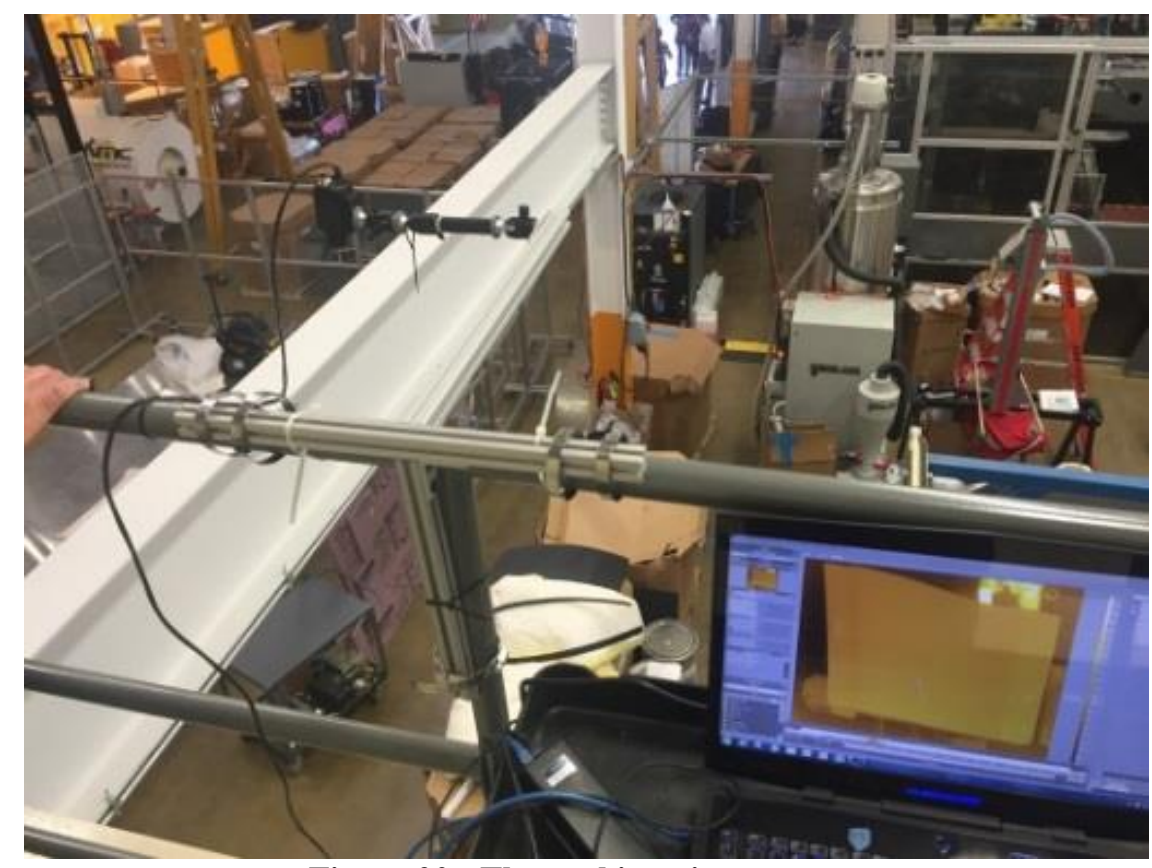

Figure 20: Thermal imaging camera.

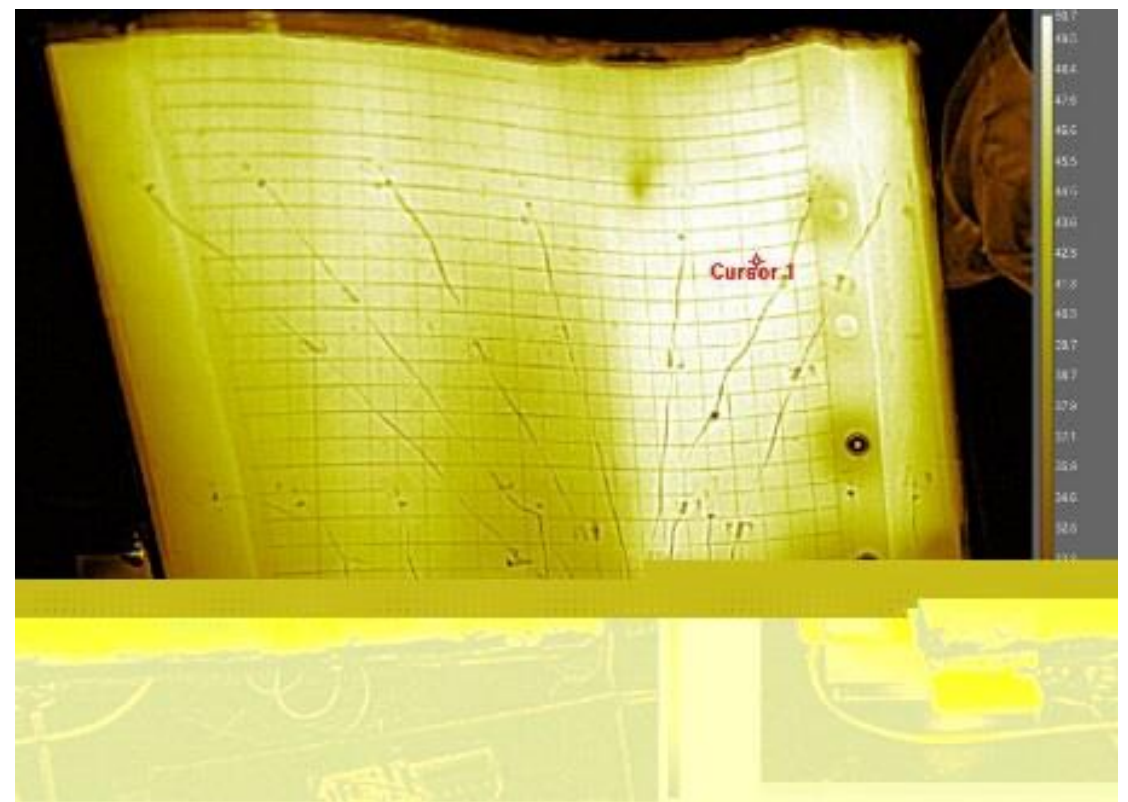

Figure 21: Output of thermal imaging camera with thermocouples. 


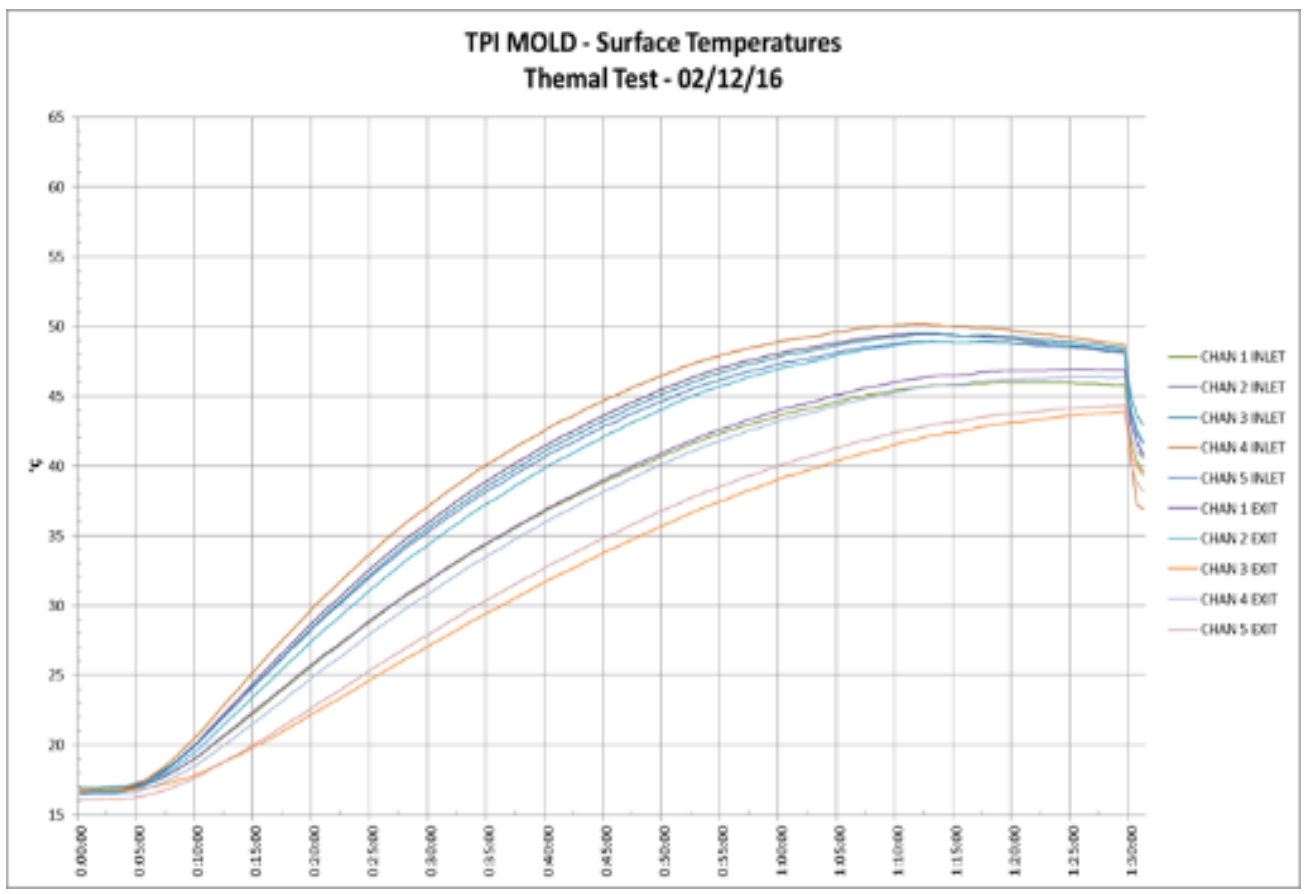

Figure 22: Thermocouple output.
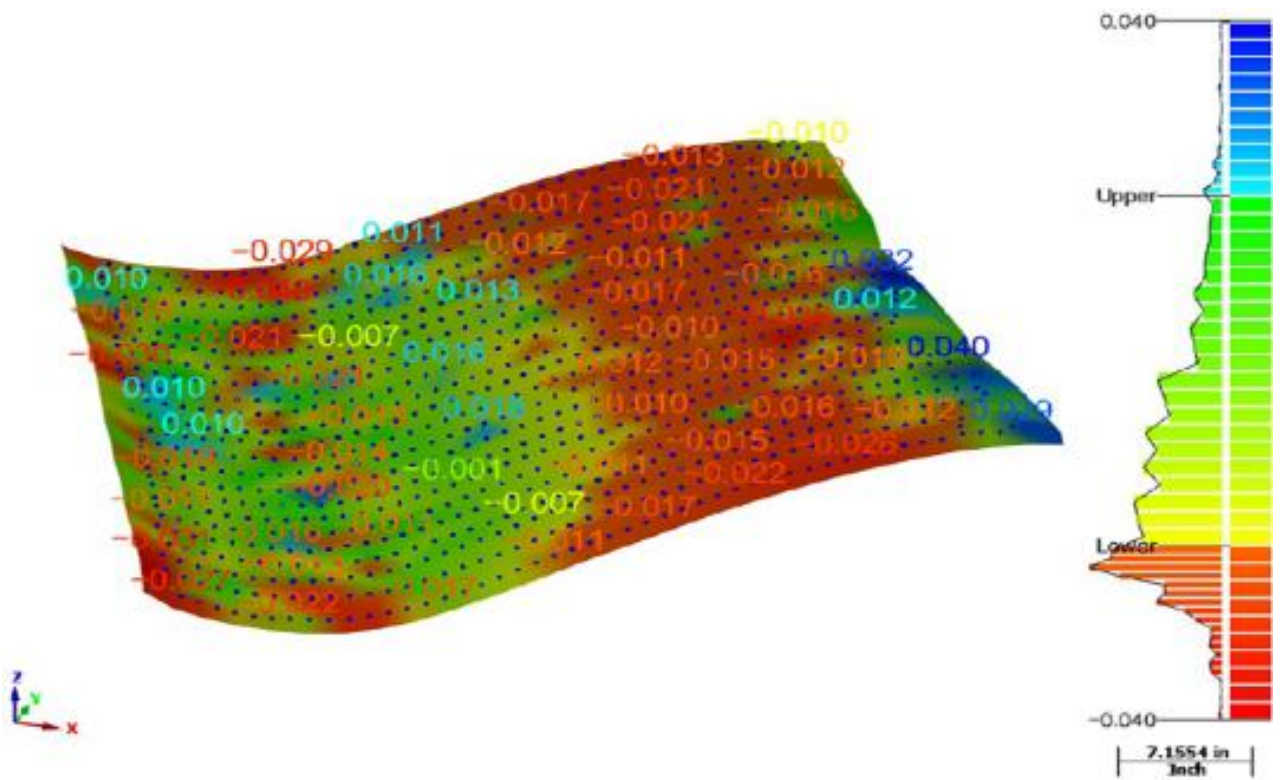

Figure 23: Surface variation.

\subsubsection{Printed Mold Manufacturing}

After successfully achieving all of the goals with the risk reduction exercise, the project transitioned to the development of a full scale $13 \mathrm{~m}$ blade mold. From the manufacturing perspective, the mold proved to be better suited for printing vertically (Figure 24). The work volume in the BAAM system was $8 \mathrm{ft}$ wide, $20 \mathrm{ft}$ long and $6 \mathrm{ft}$ in height. Therefore, each mold would be made from eight segments (Figure 25). 


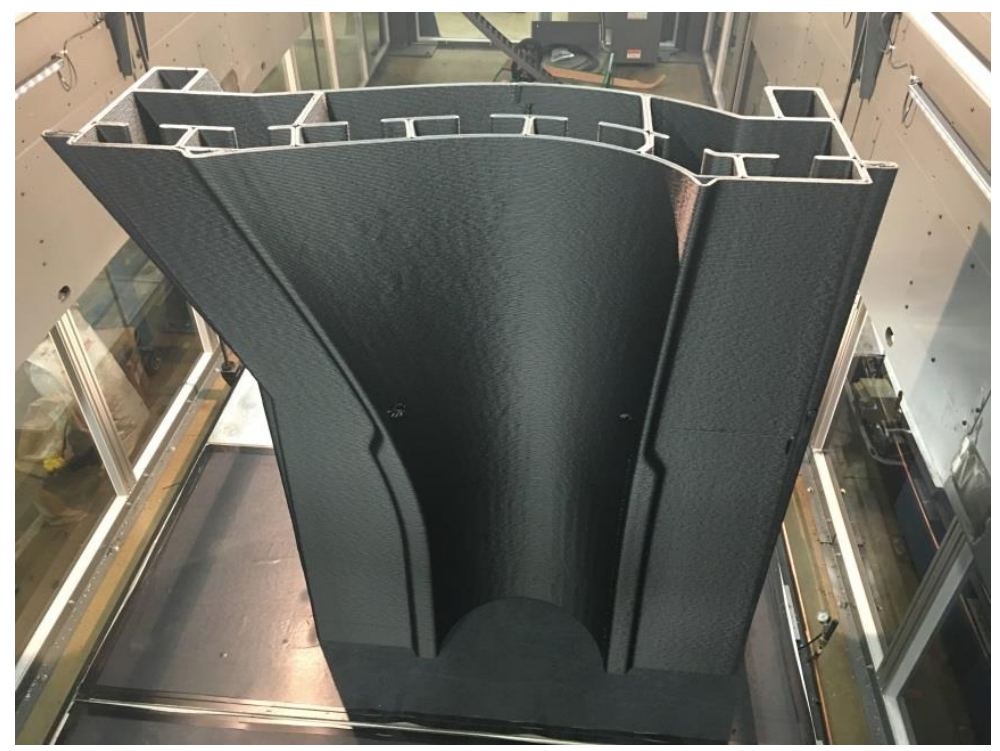

Figure 24: Printed low pressure side section 1 in the BAAM CI printer.

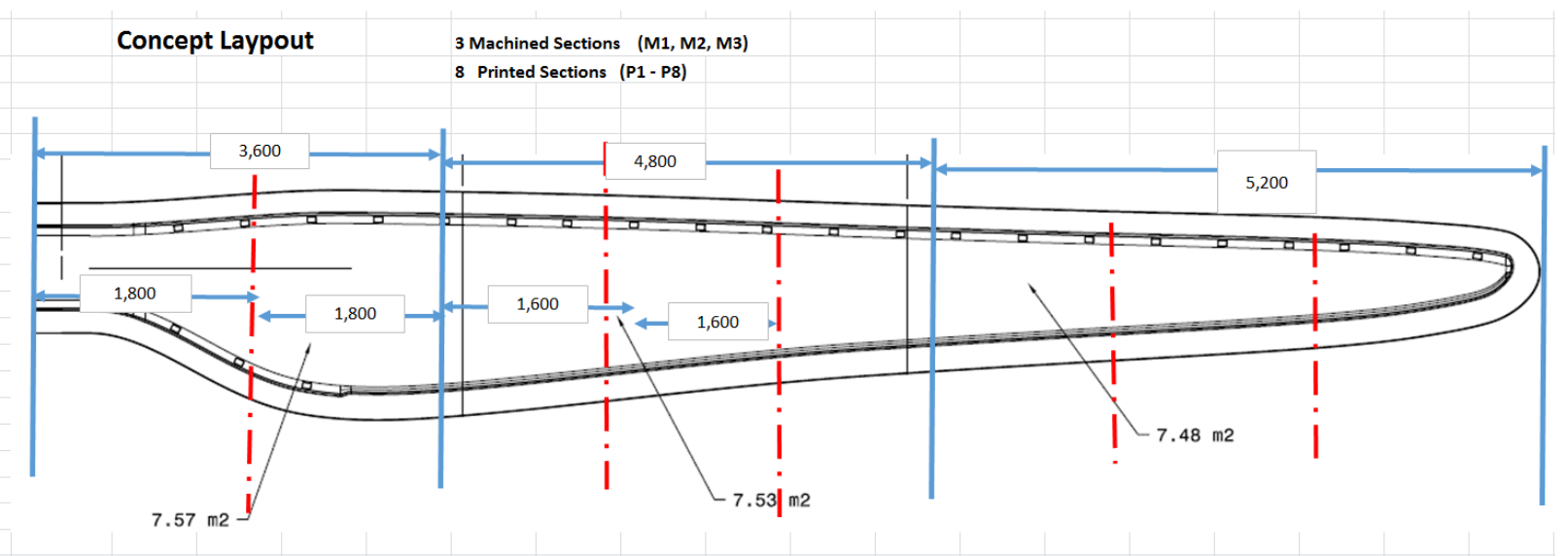

Figure 25: Mold sections.

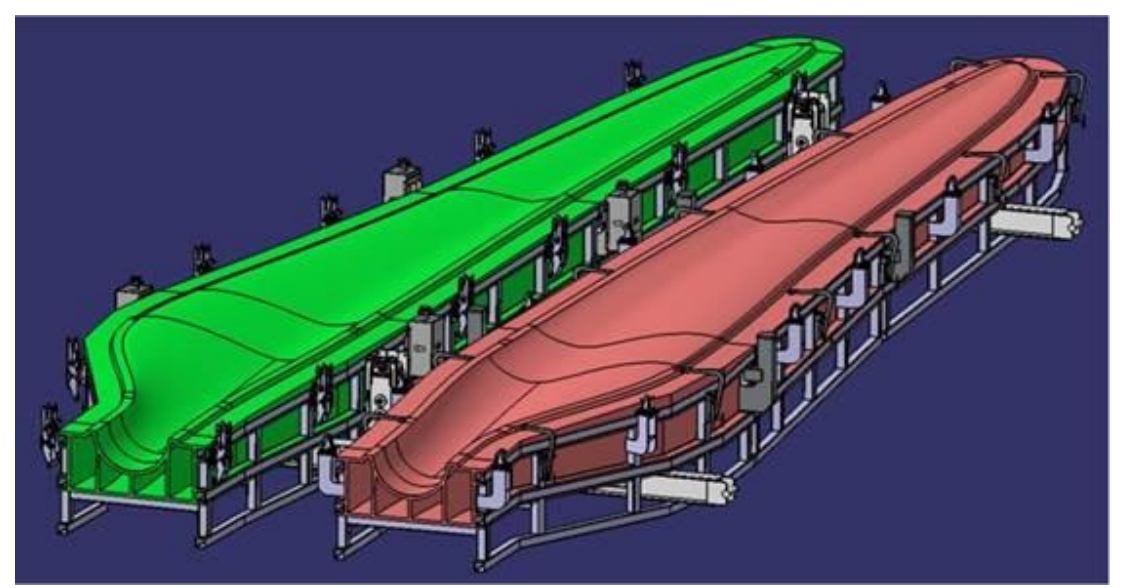

Figure 26: ORNL/TPI AM blade mold conceptual model. 
Each section is printed on end to maximize the resolution of the BAAM process and reduce the required support material as shown in Figure 24. Figure 27 shows the sections of the SWiFT AM blade mold printed mold prior to covering with fiberglass. While many of the technical opportunities of AM in wind mold production are addressed in the production of the SWiFT mold, it also serves as a tool for the evaluation of economic incentives for similar molds on larger scales.

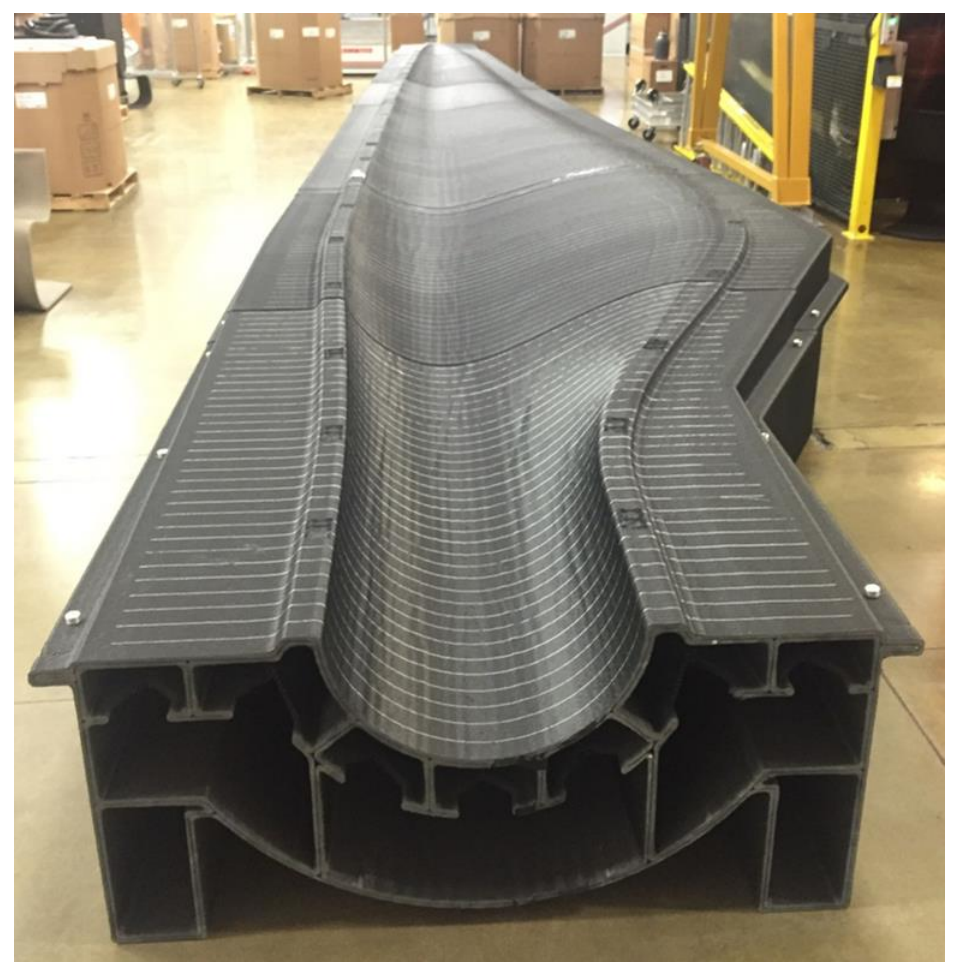

Figure 27: 5 of the 8 low pressure side SWiFT mold sections.

After completion of printing, the molds were coated with fiberglass (Figure 28) and machined to the final target surface (Figure 29). The molds were fitted to be inserted into the egg crate structure (Figure 30) and finally polished for operation (Figure 31). As of the writing of this report, one full set of blades has been manufactured (Figure 32, three in total) with no discernable wear on the molds.

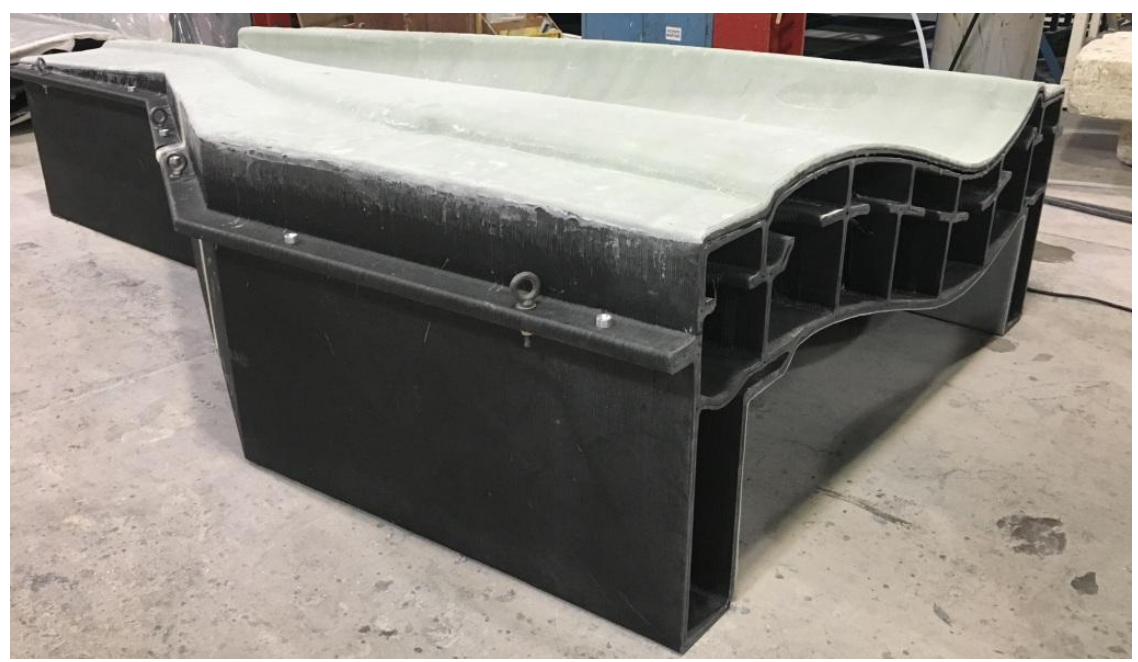

Figure 28: Coated section. 


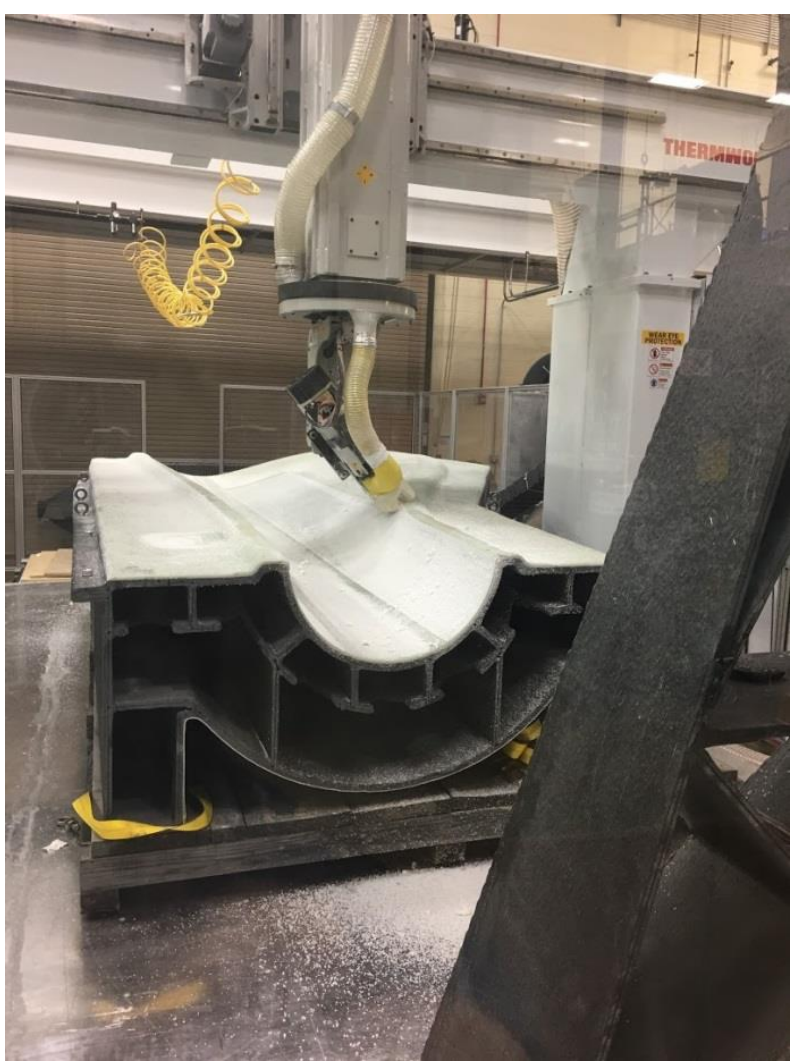

Figure 29: Section being machined.

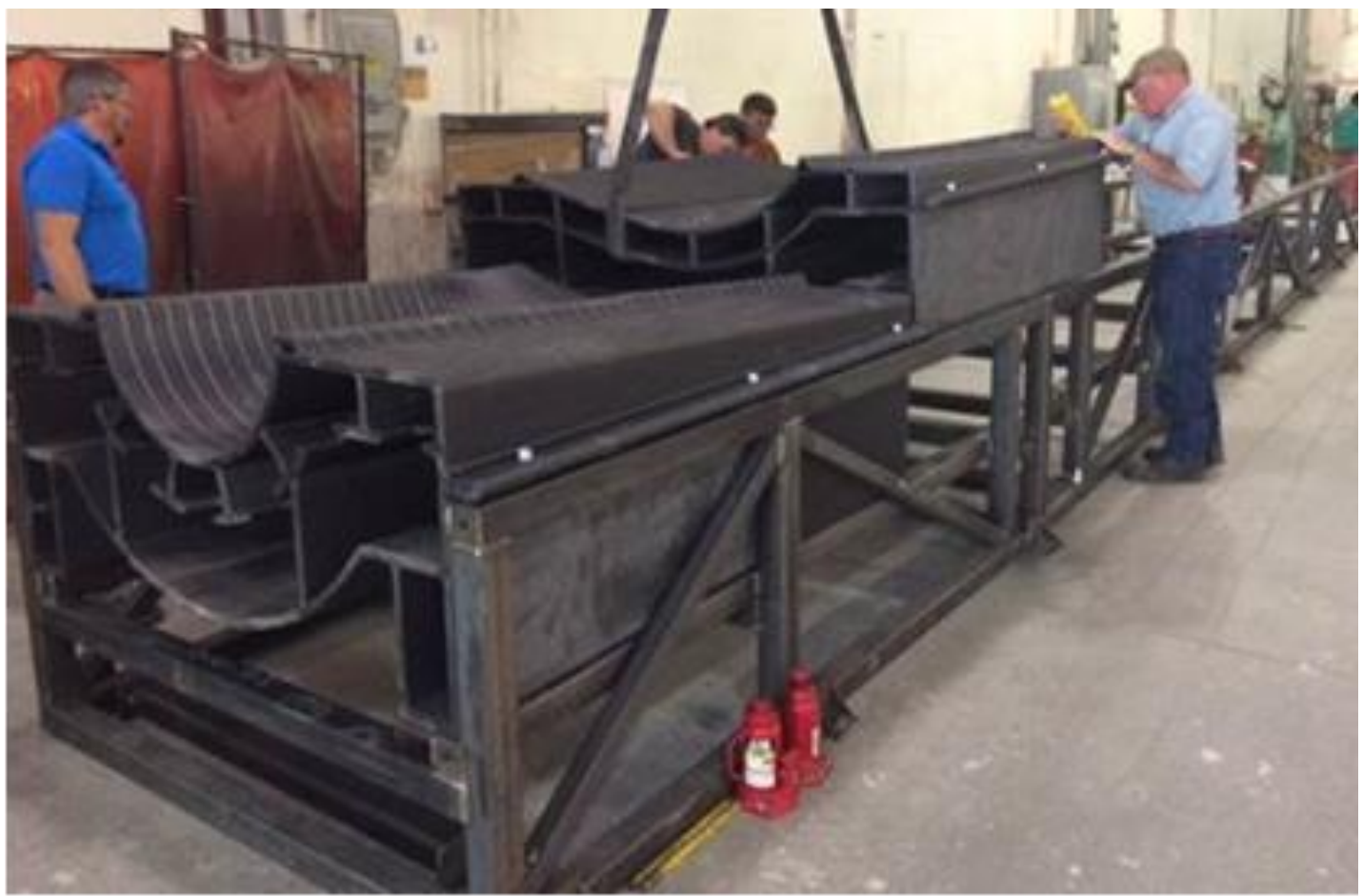

Figure 30: Sections emplaced in egg crate. 


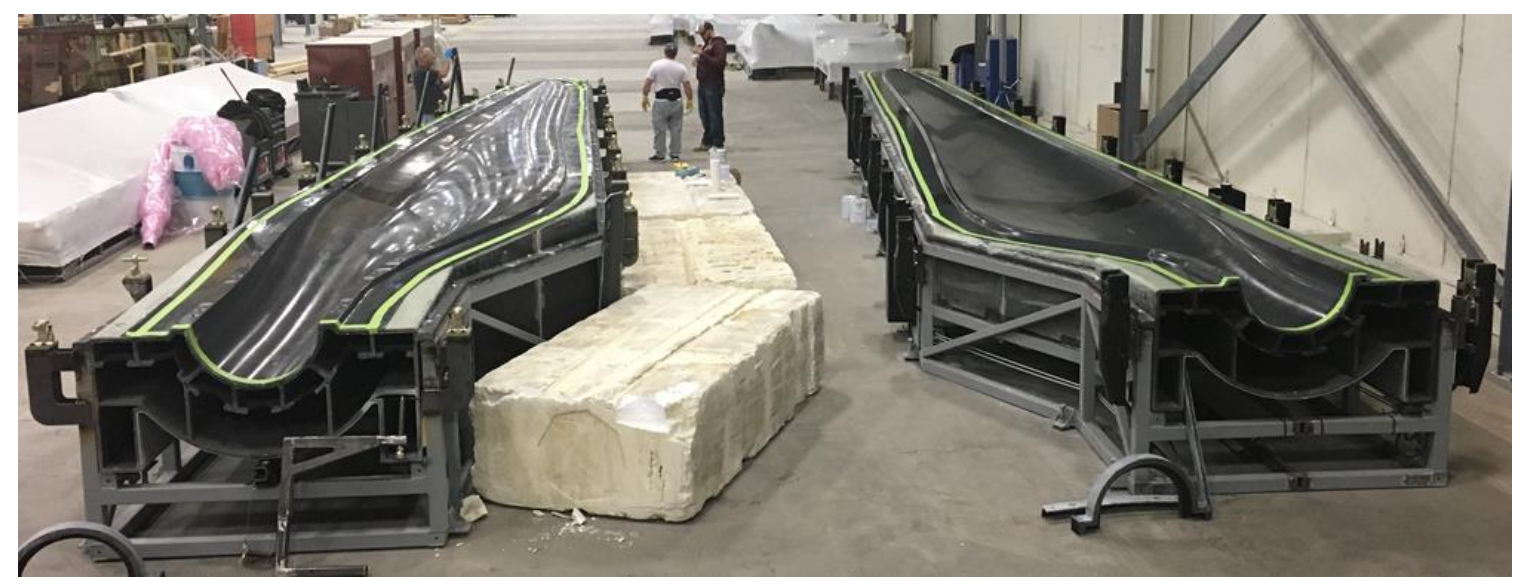

Figure 31: Final molds (high pressure and low pressure).

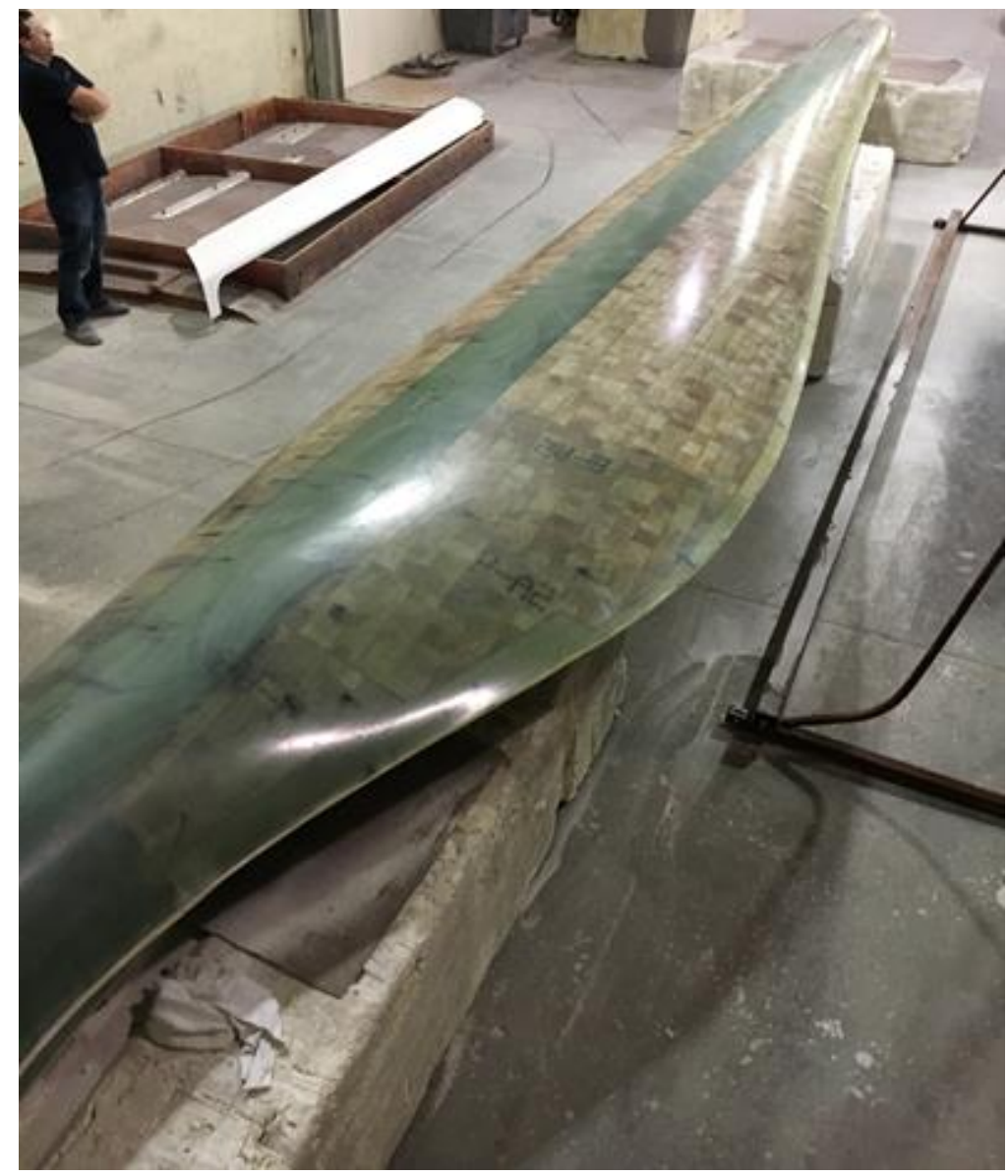

Figure 32: Finished blade.

\subsubsection{Economics of large scale AM blade mold production}

To evaluate the economics of blade mold production through AM a model has been developed which accounts for pre-processing, material, processing, and post-processing costs as previously described. Inputs to the model are broken into several categories, including blade design parameters, material costs, 
labor factors, process parameters, and mold geometry. Assumptions of course must be made to project manufacturing costs including the assembly of the steel frame and the alignment mechanisms. The exact costs of these processes are unknown at the time of reporting and should not be extrapolated to production costs from a research exercise. However, the model serves a tool to gage the relative impact of manufacturing factors on the overall cost of production.

For a 13 meter mold, as produced for the SWiFT project the cost breakdown is presented in Figure 30.

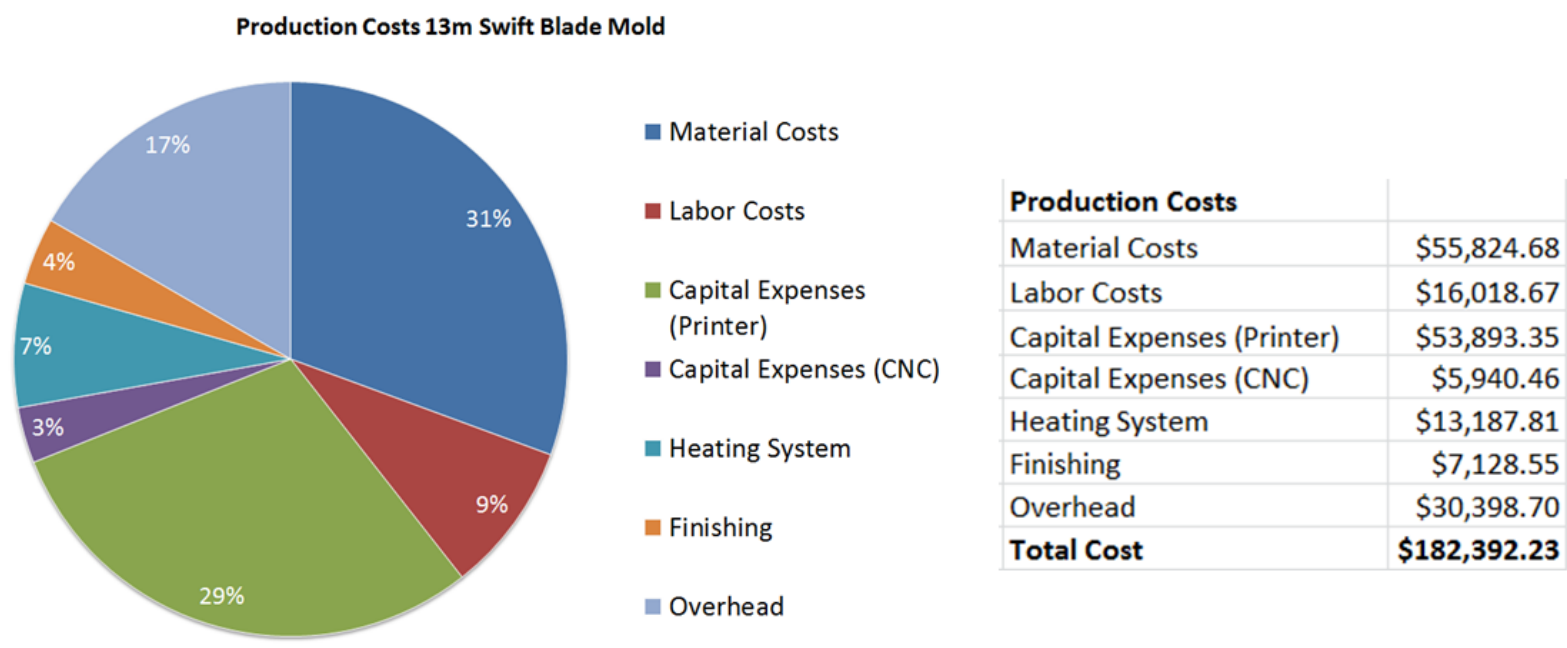

Projected Total Cost: $\$ 182,392$

Note: In a production environment

Figure 33: Costs for an AM 13m Blade Mold.

The primary costs observed are associated with material and processing costs (i.e. amortized printer cost). The quantities of which are evenly split. Compared to the previously analyzed AM processes where processing costs can reach in excess of $80 \%$ of the total costs, the increased production rate of the BAAM system reduces the production time and therefore the amortized machine cost per part. Extrapolation of the SWiFT mold parameters for the $13 \mathrm{~m}$ blade (Figure 33 ) to a $50 \mathrm{~m}$ blade design results in Figure 34. 


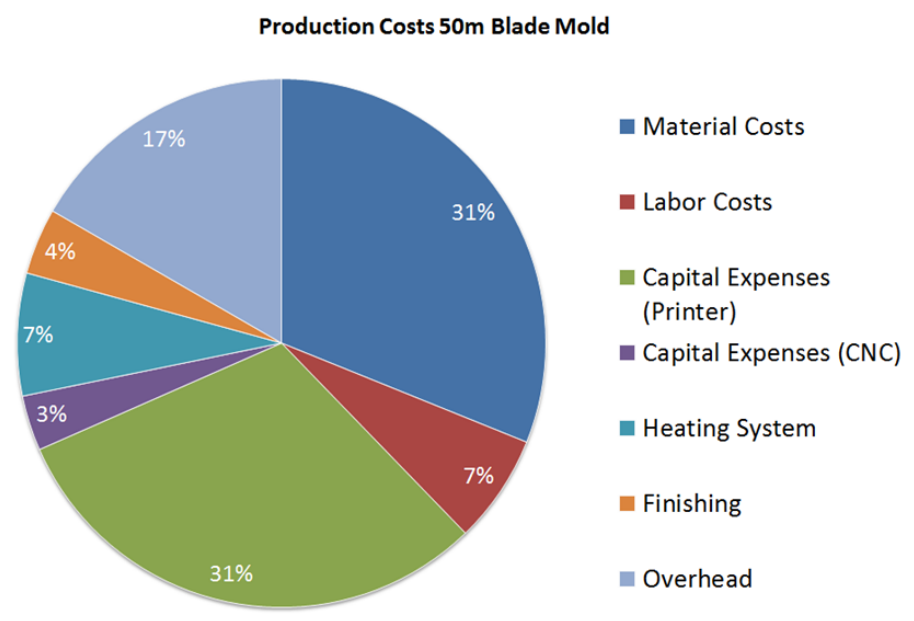

Projected Total Cost: $\$ 2,450,688$

Note: In a production environment

Figure 34: Economic analysis of an AM printed 50m mold.

Note that while the overall cost has increased significantly, the proportions of the overall cost remain consistent. This means that the model allows for the study of economic drivers in AM blade molds at scale. Given that materials and processing are the primary sources of cost impacts on these parameters will have the greatest impacts. For example, if the carbon fiber reinforced ABS used in the SWiFT blade mold was replaced with fiber glass reinforced ABS (assuming the CTE and strengths were sufficient for the mold design), the material costs could be reduced by 50\% resulting in an overall cost reduction of $20 \%$. Furthermore, without changing the material, a reduction in the mold volume of 50\% (through design) would also reduce the material costs by $50 \%$ but would also cut the processing time in half. This change would result in a total cost reduction of $41 \%$. Thus the previously held assumptions on the economics of AM are validated in the case of large scale wind molds, i.e. that the time associated with manufacturing has the single largest impact on the overall cost. Reducing the production time by reducing the mold volume both decreases the volume of material used and the processing costs. Current research is focusing on larger and even faster systems. Ingersoll Machine Tool is currently manufacturing an extremely large AM system that will produce parts at rates exceeding $1000 \mathrm{lb} / \mathrm{hr}$. This will likewise significantly drop the processing costs by over $80 \%$. Another active area of research is on finishing the printed parts. Automated coatings will significantly reduce labor costs. Therefore, the combination of lower cost feedstocks, increased production rates and development of coatings should significantly reduce manufacturing costs and lead times.

\section{IMPACTS}

The mission of EERE is to create and sustain American leadership in the transition to a global clean energy economy. Its vision is a strong and prosperous America powered by clean, affordable, and secure energy. Wind Power in the U.S. accounted for approximately 226.5 terawatt-hours, or $5.55 \%$ of all generated electrical energy. Advanced materials (carbon fiber) and manufacturing processes (such as additive manufacturing) are critical for reducing manufacturing costs and increasing the competitiveness of alternative energy sources.

The project demonstrated that, through the use of additive manufacturing, it was not only possible to bypass numerous steps in the manufacturing process (e.g. making a plug, making a custom sub structure and calibrating the mold with the truss structure), it was possible to directly integrate heating ducts into the manufacturing process, simplifying the manufacturing and assembly processes. While the current process proved feasible and cost competitive, TPI identified many other aspects of their manufacturing process that 
could benefit from large scale composite additive manufacturing. As an example, TPI is currently exploring the use of BAAM to manufacture shipping fixtures to secure the blades to trailers for transport. These fixtures are complex and typically very difficult to manufacture.

\subsection{CONCLUSIONS}

All of the target metrics for this project (described in Table 3) were either met or exceeded the defined goals. Numerous manufacturing steps were eliminated and yet the team was able to directly use the molds in production. An analysis of cost savings revealed that, with little refinement, additive manufacturing could significantly reduce manufacturing costs. First, the primary material used in this project was carbon fiber reinforced ABS which costs approximately $\$ 5 / \mathrm{lb}$. Transitioning to glass fiber reinforced $A B S$ would provide similar performance yet has a cost of approximately $\$ 2 / \mathrm{lb}$ (less than half the cost of CF ABS). Second, the productivity (manufacturing rate of $100 \mathrm{lb} / \mathrm{hr}$ ) and size (8 ft x $20 \mathrm{ft} \times 6$ $\mathrm{ft}$ ) of the current BAAM systems significantly impacts the manufacturing costs. Transitioning to a significantly high production rate $(1000 \mathrm{lb} / \mathrm{hr})$ and bed size $(23 \mathrm{ft} \times 10 \mathrm{ft} \times 210 \mathrm{ft})$ can likewise significantly drop manufacturing costs by elimination of the need for assembly (print the mold as one part at a rate $10 \mathrm{X}$ faster than the current state of the art). ORNL is currently working with Ingersoll Machine Tool on a system that can achieve these goals.

\section{PARTNER BACKGROUND}

TPI is a global provider of structural composites products for the wind energy, military, and transportation markets. TPI's advanced composites manufacturing technology allows us to build near aerospace grade parts at industrial prices. TPI products excel where high strength, light weight and durability are required. TPI has over five decades of innovation and expertise in manufacturing largescale composite structures of highest quality at a competitive total delivered cost to our customers. TPI is a leading manufacturer of wind blades to major turbine manufacturers in the United States, Europe, and Asia. TPI's proprietary processes and manufacturing expertise have also been applied to create first-oftheir-kind composite solutions. 


\section{REFERENCES}

Holshouser, C., C. Newell, S. Palas, L. J. Love, V. Kunc, R. F. Lind, P. D. Lloyd, J. C. Rowe, C. A. Blue and C. E. Duty (2013). "Out of bounds additive manufacturing." Advanced Materials and Processes 171(3).

Love, L. J., V. Kunc, O. Rios, C. E. Duty, A. M. Elliott, B. K. Post, R. J. Smith and C. A. Blue (2014). "The importance of carbon fiber to polymer additive manufacturing." Journal of Materials Research 29(17): 1893-1898.

Monzon, M., , Gibson, I., Benitez, A., Lorenzo, L., Hernandez, P., Marrero, M. (2013). "Process and material behavoir modeling for a new desig of micro-additive fused deposition." International Journal of Manufacturing Technology 67: 2217-2726.

Salmi, E. A. a. A. (2012). "Economics of Additive Manufacturing for End-Use Metal Parts." International Journal of Advanced Manufacturing Technology: 1147-1155.

Tekinalp, H. L., V. Kunc, G. M. Velez-Garcia, C. E. Duty, L. J. Love, A. K. Naskar, C. A. Blue and S. Ozcan (2014). "Highly oriented carbon fiber-polymer composites via additive manufacturing."

Composites Science and Technology 105: 144-150.

Wohlers, T. (2015). Wohlers Report 2015. Fort Collins, Wohlers Associates, Inc. 